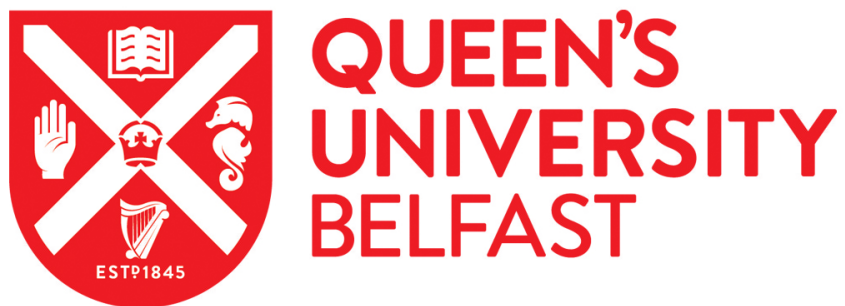

\section{Immune regulation in the aging retina}

Chen, M., Luo, C., Zhao, J., Devarajan, G., \& Xu, H. (2019). Immune regulation in the aging retina. Progress in Retinal and Eye Research, 69, 159-172. https://doi.org/10.1016/j.preteyeres.2018.10.003

\author{
Published in: \\ Progress in Retinal and Eye Research
}

Document Version:

Peer reviewed version

Queen's University Belfast - Research Portal:

Link to publication record in Queen's University Belfast Research Portal

\section{Publisher rights}

Copyright 2018 Elsevier Ltd.

This manuscript is distributed under a Creative Commons Attribution-NonCommercial-NoDerivs License

(https://creativecommons.org/licenses/by-nc-nd/4.0/), which permits distribution and reproduction for non-commercial purposes, provided the author and source are cited.

\section{General rights}

Copyright for the publications made accessible via the Queen's University Belfast Research Portal is retained by the author(s) and / or other copyright owners and it is a condition of accessing these publications that users recognise and abide by the legal requirements associated with these rights.

Take down policy

The Research Portal is Queen's institutional repository that provides access to Queen's research output. Every effort has been made to ensure that content in the Research Portal does not infringe any person's rights, or applicable UK laws. If you discover content in the Research Portal that you believe breaches copyright or violates any law, please contact openaccess@qub.ac.uk. 


\title{
Immune regulation in the aging retina
}

\author{
Mei Chen ${ }^{1}$, Chang Luo ${ }^{1,2}$, Jiawu Zhao ${ }^{1}$, Gayathri Devarajan ${ }^{3}$, Heping $\mathrm{Xu}^{1,2,{ }^{*}}$ \\ ${ }^{1,}$ Centre for Experimental Medicine, School of Medicine, Dentistry \& Biomedical Sciences, \\ Queen's University Belfast, UK \\ 2, Aier Eye Institute, Aier School of Ophthalmology, Central South University of China \\ 3, Infection and Immunity, School of Medicine, University of Aberdeen, UK \\ *, Corresponding to: Heping Xu, Centre for Experimental Medicine, School of Medicine, \\ Dentistry \& Biomedical Sciences, Queen's University Belfast, 97 Lisburn Road, Belfast, BT9 \\ 7BL, UK. Email: heping.xu@qub.ac.uk
}

\section{Authors contributions:}

Percentage of work contributed by each author in the production of the manuscript is as follows: Mei Chen: 28\%, Chang Luo: 4\%, Jiawu Zhao: 4\%, Gayathri Devarajan: 4\%, Heping Xu: 60\% 


\begin{abstract}
The retina is an immune privileged tissue, which is protected from external and internal insults by its blood-retinal barriers and immune suppressive microenvironment. Apart from the avoidance and tolerance strategies, the retina is also protected by its own defense system, i.e., microglia and the complement system. The immune privilege and defense mechanisms work together to maintain retinal homeostasis. During aging, the retina is at an increased risk of developing various degenerative diseases such as age-related macular degeneration, diabetic retinopathy, and glaucomatous retinopathy. Previously, we have shown that aging induces a para-inflammatory response in the retina. In this review, we explore the impact of aging on retinal immune regulation and the connection between homeostatic control of retinal immune privilege and para-inflammation under aging conditions and present a view that may explain why aging puts the retina at risk of developing degenerative diseases.
\end{abstract}

Key words: retinal degeneration, inflammation, blood retina barrier, microglia, complement, aging 


\section{Contents}

1. Introduction

2. Retinal immune privilege

2.1. The blood retinal barrier

2.2. Retinal immune regulation

2.3. Intraocular antigen-induced systemic immune regulation

3. The impact of aging on retinal immune privilege

3.1. Age-related changes in retinal barriers

3.2. The impact of age on retinal immune regulation

3.2.1. The TREM2-DAP12 pathway in the aging retina

3.2.2. The CX3CL1-CX3CR1 pathway in the aging retina

3.2.3. The CD200-CD200R pathway in the aging retina

3.2.4. The CD47-SIRP (CD172) pathway in the aging retina

3.2.5. The endocannabinoid system in the aging retina

3.2.6. The impact of age on RPE immune regulation

3.3. The impact of age on retinal immune effectors

3.3.1. Altered microglial response in the aging retina

3.3.1.1. Microglial functional alteration in the aging retina

3.3.1.2. Transcriptomic changes in aging microglia

3.3.1.3. Age-related metabolic alteration and retinal microglial activation

3.3.2. Altered complement response in the aging retina

3.4. Age-related changes in intraocular compartment mediated systemic immune regulation

4. The impact of systemic inflammation in the aging retina

5. Conclusions and therapeutic implications

Acknowledgements

References 


\section{Abbreviations}

2-AG: 2-arachidonoyl-glycerol

ACAID: anterior chamber-induced

immune deviation

AEA: arachidonoyl-ethanolamide

AMD: age-related macular degeneration

AQP4: aquaporin 4

BRB: blood retina barrier

C1INH: C1-inhibitor

C1q: complement component 1q

CB1: cannabinoid receptor type 1

CB2: cannabinoid receptor type 2

CCL2: chemokine (C-C motif) ligand 2

CCR2: C-C chemokine receptor type 2

CFB: complement factor B

CFH： complement factor $\mathrm{H}$

CNS: central nervous system

CTLA2: cytokine T-lymphocyteassociated protein 2

CTLA4: cytokine T-lymphocyteassociated protein 4

CX3CL1: chemokine (C-X3-C motif) ligand 1

CX3CR1: CX3C chemokine receptor 1

DAM: disease associated microglia

DAMP: damage-associated molecular pattern

DAP12: DNAX activation protein 12
EAU: experimental autoimmune uveoretinitis

FasL: Fas ligand

GL: ganglion layer

iBRB: inner blood retina barrier

INL: inner nuclear layer

IPL: inner plexiform layer

NVU: neurovascular unit

oBRB: outer blood retinal barrier

ONL: outer nuclear layer

OPL: outer plexiform layer

oxPOS: oxidized photoreceptor outer segments

POS: photoreceptor outer segments

RPE: retinal pigment epithelium

SIRP: signal-regulatory protein

SMA: smooth muscle actin

TGF: transforming growth factor

TREM2: triggering receptor expressed on myeloid cell 2

TLR: Toll-like receptor

TRAIL: tumor Necrosis Factor-related apoptosis-inducing ligand

TSP-1: thrombospondin 1

VCAID: vitreous cavity-induced immune deviation

ZO-1: zonula occludens-1 


\section{Highlights}

$\diamond \quad$ Localized disruption of $\mathrm{iBRB}$ and oBRB exists in the normal aging retina.

$\diamond \quad$ Immune regulatory cues from neurons and RPE cells are altered in the aging retina.

$\diamond$ The clearance function of retinal microglia is reduced during aging.

$\diamond$ Microglial response to DAMPs shifts towards an inflammatory phenotype during aging.

$\diamond \quad$ The aging retina is more susceptible to further insults. 


\section{Introduction:}

Avoidance, tolerance and resistance are strategies utilized by the host to protect it from external and internal insults. Avoidance reduces the risk of exposure to danger (or pathogens). Resistance reduces damage caused by pathogens, and tolerance reduces the negative impact of the pathogen on host fitness without directly affecting the pathogen burden (Medzhitov et al., 2012). Resistance is active defense, whereas avoidance and tolerance can be viewed as passive defense (although, immunological tolerance to specific antigens is often achieved through an active mechanism). Homeostasis and functionality are maintained at the tissue level also by these defense strategies. The retina, for example, avoids pathogens and systemic inflammatory disturbance by insulating itself from the rest part of the body using physical barriers, i.e., the blood retina barriers (BRBs). Its tolerance strategy is to utilize specialized mechanisms to suppress inflammation and subsequent immunopathology. Avoidance and tolerance together warrant the immune privilege status of the retina. The resistance mechanism is operational when pathogens breach the BRBs, or when danger molecules arise within the retina. Subsequently, pathogenic burden is reduced, and danger molecules are eliminated so homeostasis can be maintained. Resistance is attained by retinal microglia and the complement system when threats are mild and transient (para-inflammation) ( $\mathrm{Xu}$ et al., 2009). Infiltrating immune cells further support the retina when threat is over the threshold (Chen and Xu, 2015).

The average lifespan of human beings has increased dramatically with the improvement of our health care and modernization of our society. Prevalence of age-related diseases, including age-related visual loss has radically increased. Aging is believed to be an important risk factor in the development of degenerative and angiogenic diseases, such as age-related macular degeneration (AMD), diabetic 
retinopathy (DR) and glaucomatous retinopathy, although, the etiology is yet to be elucidated (Ardeljan and Chan, 2013, Luu and Palczewski, 2018). All the age-related retinal diseases have two features in common, the disruption of retinal homeostasis and low-grade chronic inflammation (parainflammation). Previously, we discussed retinal para-inflammation in the aging eye (Xu et al., 2009), which represents the resistance strategy of the neuroretina against age-mediated endogenous insults. In this article we discuss retinal immune regulation under aging conditions, with a particular focus on retinal avoidance and tolerance strategies, and explore how aging puts the retina at risk of developing various degenerative diseases.

\section{Retinal immune privilege}

A fine structure of retinal neurons is essential for visual function. This structural requirement for function makes the retina extremely vulnerable to internal and external insults. In addition, the retina has a poor renewal and repair capacity, alongside a low functional autonomy. As a result, the consequences of even minor damage to the retina can be devastating. Nature has developed specialized avoidance and tolerance strategies to minimize and prevent retinal disturbance, e.g., retinal immune privilege (Forrester and Xu, 2012, Gregerson, 1998, Streilein et al., 2002). Retinal cells (such as neurons) are privileged from systemic immune surveillance. Intraocular compartments, such as the anterior chamber, vitreous cavity and the subretinal space, are immune privileged sites. When foreign antigens are exposed to these compartments they induce tolerance instead of immune rejection (Ferguson and Griffith, 1997, Streilein, 1995). The mechanism that maintains retinal immune privilege can be viewed as layered protections (Caspi, 2006). BRBs provide the first layer of protection to the retina. Once the barrier is breached, retinal cells operate the second layer of protection by suppressing the local inflammatory response to reduce immunopathology. In 
conjunction, the antigenic signals from pathogens in the intraocular compartments are sent to the systemic immune system, and an antigen-specific tolerance or a suppressive immune response is induced, which offers the third layer of protection.

\subsection{The blood-retinal barrier}

The retinal-immune barrier consists of three components. (1) Inner blood-retina barrier (iBRB); formed by tight junctions between retinal vascular endothelial cells. (2) Outer blood-retinal barrier (oBRB); formed by tight junctions between retinal pigment epithelial (RPE) cells. (3) Blood-aqueous barrier; formed by tight junctions in the non-pigmented epithelial layer of the ciliary body and the endothelium of the iris vasculature. These barriers insulate the retina from exogenous pathogens, segregate the tissue from the systemic immune system and avoid immune surveillance. A functional iBRB is maintained by the neurovascular unit (NVU) (Metea and Newman, 2007), which consists of vascular endothelial cells, pericytes, glial cells, and neurons (Muoio et al., 2014).

\subsection{Retinal immune suppression}

When pathogens break through the BRBs, the second layer of protection is triggered. The retina employs a strategy to reduce the immune response which minimizes immunopathology. This includes the induction of retinal cell tolerance to invading pathogens and suppression of immune cell activation. For example, opportunistic pathogens can persist as latent infections (although they can be reactivated, particularly in immunocompromised individuals). Retinal immune suppression is achieved by various neuro-immune regulatory proteins. These proteins control microglial or macrophage activation (e.g., via the CX3CL1, CD200, CD47, and endocannabinoids pathways), T cell activation (e.g., via

thrombospondin-1, TGF- $\beta$, CTLA4, CTLA2, etc.) (Horie et al., 2010, Kawazoe et al., 2012, 
Mochizuki et al., 2013, Sugita et al., 2008, Sugita et al., 2009, Zamiri et al., 2005), or complement activation (via expression of various complement regulators such as $\mathrm{CFH}, \mathrm{CD} 46, \mathrm{CD} 55$, CD59, etc.), and induction of immune cell death (e.g., via the Fas ligand (FasL) and Tumor Necrosis Factor-related apoptosis-inducing ligand (TRAIL)) (Ferguson and Griffith, 1997, Ferguson and Griffith, 2007, Kazama et al., 2008). Mechanisms related to regulation of effector cells (i.e., immune cells and RPE cells) have been the main focus when researching the second layer of protection. Whether or not the retina can also control pathogens, for example, by restricting or reducing their toxic effects remains unknown.

\subsection{Intraocular antigen-induced systemic regulation}

When antigens are inoculated into the anterior chamber, vitreous cavity or subretinal space, they can induce antigen-specific systemic immune suppression. Ocular $\mathrm{F} 4 / 80^{+}$macrophages and intraocular levels of TGF $\beta 2$ are crucial for the generation of antigen-specific, immune suppressive T or B cells (Egan et al., 1996, Streilein, 1999). Anterior chamber-induced immune deviation (ACAID) (Streilein, 1995), vitreous cavity-induced immune deviation (VCAID) and subretinal space-induced immune deviation (Jiang et al., 1993, Wenkel et al., 1999) are examples of the third layer of protection. This is important when the first and second layers of protection fail, and antigens enter the intraocular compartment, for example, in ocular injury. A controlled immune response to the invading antigen will minimize immunopathology and may offer protection to foreign materials or proteins inoculated into the eye through intraocular drug deliver or by gene therapy.

Although multiple types of cells are involved in the layered protection of the neuronal retina (Caspi, 2006), this review discusses predominately the role of microglia and the complement system in retinal immune regulation under aging conditions. The discussion on Muller glia, astrocytes and endothelial 
cells is rather limited.

\section{The impact of age on retinal immune privilege}

\subsection{Age-related changes in retinal barriers}

A functional iBRB is maintained by the NVU (Metea and Newman, 2007). Senescence of NVUrelated cells may affect the integrity and function of the iBRB. An age-related reduction in the number of astrocytes has been observed in the rat retina (Mansour et al., 2008). Müller cells from aging eyes contain a great abundance of oxidized lipid (4-hydroxy-2-nonenal) (Nag et al., 2011). Endothelial loss and cellular senescence of neurons have been reported in the aging human retina (Lopez-Luppo et al., 2017). Importantly, a progressive structural and functional deterioration of the NVU has been observed in the aging rat retina. This is characterized by thickening of the basement membrane, altered length and orientation of desmin filaments of pericytes, widespread alpha-smooth muscle actin ( $\alpha$-SMA) distribution (Hughes et al., 2006), followed by capillary loss, aneurysms, and distorted, leaky vessels (Chan-Ling et al., 2007, Hughes et al., 2006). Despite the structural and functional deterioration of the iBRB, T or B cells were not detected in the normal aging retina (Figure 1). Aged retinas present with mild microglial activation and complement activation (Chen et al., 2010, Xu et al., 2009), which may result from age-related oxidative damage or leakage of plasma proteins from the iBRB.

Previously, we have shown that RPE cells undergo significant morphological changes where they increase in size and become multinucleated during aging (Chen et al., 2016). If the enlarged cell fails to multinucleate it may collapse (Chen et al., 2016). When triple-staining of RPE flatmounts for F- 
actin, ZO-1 and claudin-1, we observed localized loss of ZO-1 but not claudin-1 and F-actin in RPE cells of aged mice (Figure 2A), suggesting tight junction disruption in the oBRB.

Previously, we and others reported an age-dependent accumulation of subretinal phagocytes (Combadiere et al., 2007, Xu et al., 2008), which may result from the low-levels of RPE damage. Recent evidence suggests that a proportion of subretinal Iba- $1^{+}$cells are recruited from circulation (Hu et al., 2015, Sennlaub et al., 2013). Interestingly, $\mathrm{CD}^{+} \mathrm{T}$ cells (Figure 2B) were not detected in RPE flatmounts from mice between 16-24 months old. Isolectin-B4 labels active microglia (Chen et al., 2010, Chen et al., 2013) and a proportion of Iba- $1^{+}$cells are Isolectin-B4 ${ }^{+}$(Figure 2C), suggesting the heterogeneous activation of subretinal phagocytes.

Structural alterations of the BRB suggest failure of the avoidance strategy, whereas microglial activation and macrophage infiltration are an indication of active resistance in the aging eye. Surprisingly, there is no retinal oedema or infiltration $\mathrm{T}$ or B lymphocytes in the aging retina. A possible explanation is that BRB breakdown in the normal aging eye is localized and transient, and the infiltrating $\mathrm{T}$ or B cells or leaking fluids are rapidly removed from the neuronal retina. An agedependent increase of the potassium channel (Kir4.1) and water channel (aquaporin 4) has been observed in brain glial cells (astrocytes) (Gupta and Prasad, 2013). Whether they are also upregulated in the aging retina remains elusive. It is also possible that disrupting the barrier solely may not be sufficient to cause retinal oedema or detectable levels of lymphocyte infiltration. Additional signals such as VEGF from an ischemic retina or chemokines from an inflamed retina would be required. High levels of inflammatory cytokines or retinal specific $\mathrm{T}$ cells/antibodies in the circulation may penetrate the barrier and cause retinal inflammation and oedema. Such pathologies are seen in experimental endotoxin induced uveoretinitis (Rosenbaum et al., 1980) and retinal peptide 
immunization induced experimental autoimmune uveoretinitis (EAU) (Caspi et al., 1986, Chan et al., 1985, Mochizuki et al., 1985). Patients with geographic atrophy do not exhibit significant immune cell infiltration or macular oedema, despite the complete loss of the oBRB at the lesion site. Within the atrophic area, photoreceptors are degenerated, and oxygen consumption is reduced. Therefore, the macula unlikely suffers from ischemia and will not send signals to vascular endothelial cells to induce leakage and macular oedema.

\subsection{The impact of age on retinal immune regulation}

Retinal cells possess immune regulatory properties which act as the second layer of retinal protection (Caspi, 2006) and can also be viewed as a tolerance strategy to maintain homeostasis. During aging, retinal cells are subjected to increasing levels of oxidative stress, which affects their neuronal functions and immune regulatory properties. Under normal physiological conditions, neurons keep retinal microglia and the complement system under control by producing various membrane and soluble forms of inhibitory molecules. When circulating immune cells infiltrate the retina, these molecules can either induce the death of the immune cells or convert them into immunosuppressive cells to reduce immunopathology.

Microglia reside in the inner part of the neuronal retina, including the ganglion layer and the inner and outer plexiform layers (Chen and Xu, 2015, Karlstetter et al., 2015). Microglia are activated upon engagement with pathogens or damage-associated molecular patterns (DAMPs) through various pathogen recognition receptors (PRRs), such as the Toll-like receptors (TLRs) and Nod-like receptors (NLRs) (Lehnardt et al., 2006, Provis et al., 1995). In particular, the Triggering Receptor Expressed on Myeloid cells 2 (TREM2) and DNAX activation protein 12 (DAP12) signaling is essential for CNS homeostasis (Colonna, 2003, Painter et al., 2015). Activation of TREM2-DAP12 initiates signal 
transduction pathways that promote microglial activation and phagocytosis.

Microglial activation is regulated by various signals from retinal neurons, such as the chemokine CX3CL1 (fractalkine) (A. E. Cardona et al., 2006, Mizuno et al., 2003, Raoul, Keller et al., 2008), TGF- $\beta$ (Paglinawan et al., 2003), endocannabinoids (Battista et al., 2006, Hernangomez et al., 2014, Mecha et al., 2016), and nerve growth factor (De Simone et al., 2007). Additionally, various cell surface molecules expressed by neurons also play an important role in controlling microglial activation by direct neuron-microglia interaction. Examples of these regulatory signals include the CD200/CD200R (Dick et al., 2003, Hernangomez et al., 2014) and CD47-SIRP (Zhang et al., 2015) pathways and other complex formations of triggering receptors expressed on myeloid cells and ligands on neurons (Figure 7A).

\subsubsection{The TREM2-DAP12 pathway in the aging retina}

TREM2 can recognize and bind to various ligands including dead cells and exogenous pathogens. The primary role of the TREM2-DAP12 complex is mediated through the Immunoreceptor Tyrosinebased Activation Motifs (ITAM) of DAP12 (Mecca et al., 2018). TREM2 is a key negative regulator of autoimmunity and plays an important role in the inhibition of IL6 and TNF $\alpha$. TREM 2 is also responsible for DAP12-induced inhibition of the inflammatory response driven by TLR agonists (Helming et al., 2008, Turnbull et al., 2006). TREM2-DAP12 signaling is required to sustain the trophic function of microglia in the aging brain (Poliani et al., 2015). Furthermore, it plays a positive role in phagocytosis of dead neurons and is critically involved in CNS homeostasis (Piccio et al., 2007). TREM2 is a marker for recently identified Disease Associated Microglia (DAM). DAM also express CD11c and CFSR, and have reduced expression of CX3CR1 (Keren-Shaul et al., 2017). DAM are only detected in the diseased CNS, particularly around the lesion, where they phagocytize debris 
and protein aggregates (Keren-Shaul et al., 2017). TREM2 is essential for the transition of resting microglia into active DAM (Keren-Shaul et al., 2017, Yeh et al., 2017).

Exactly how aging impacts the TREM2-DAP12 signaling in the retina remains elusive. Expression levels of TREM2 in microglia from the CNS are reduced in aged mice (Hickman and El Khoury, 2014, Mecca et al., 2018). Since this signaling pathway is required for microglial proliferation and survival (Poliani et al., 2015), it is possible that a progressive decline in TREM2 expression might impair the microglial response to damaged neurons. Interestingly, retinal aging is accompanied by an increased number and density of microglia (Chen et al., 2013, Li et al., 2015). Further investigation into the dynamic change of TREM2 expression in the aging retina will help reveal its role in retinal immune regulation.

\subsubsection{The CX3CL1-CX3CR1 pathway in the aging retina}

In the CNS, including the neuronal retina, CX3CR1 is expressed by microglia and CX3CL1 by neurons as a transmembrane protein (Harrison et al., 1998, Ludwig and Mentlein, 2008). The membrane form of CX3CL1 in neurons function predominately as an integrin-type adhesion molecule that can initiate signaling transduction, rather than a chemokine. The CX3CL1-CX3CR1 axis mediated neuron-microglia interaction plays an important role in modulating physiological activities of the brain during development, adulthood and aging. CX3CL1-CX3CR1 signaling is known to be involved in synaptic pruning, promoting survival of neurons and neural precursors, modulating synaptic transmission and plasticity. When neuronal damage occurs, microglia rapidly react to protect or eliminate dead neurons. The rescue process may be mediated by the production of soluble factors essential for neuron survival, modulation of phagocytic activity or an indirect effect upon other cells in the retinal parenchyma. 
The CX3CL1-CX3CR1 axis also controls microglial activation. Early in vitro studies demonstrated that CX3CL1 could block LPS- and IFN $\gamma$-induced release of cytokines (interleukin-1 $\beta$ (IL-1 $\beta$ ), TNF $\alpha$, 8-isoprostane, nitric oxide (NO) and IL-6) in cultured microglia (Mizuno et al., 2003, Zujovic et al., 2000). Under diabetic conditions, deletion of CX3CR1 resulted in significantly higher levels of IL$1 \beta$ and VEGF expression along with increased retinal microglial activation (Cardona et al., 2015). CX3CR1 deficient mice present an exaggerated microglial response to paraquat-mediated retinal damage with excessive expression of inflammatory cytokines (TNF $\alpha$, iNOS, IL-1 $\beta$, CCL2) (Chen, Luo et al., 2013). Mononuclear phagocytes from CX3CR1 deficient mice express higher levels of P2X7 which stimulate IL-1 $\beta$ maturation, secretion and photoreceptor degeneration (Hu et al., 2015).

During aging, the expression level of CX3CL1 is reduced, which is accompanied by increased microglial activation (Mecca et al., 2018). Aged CX3CR1 KO mice present with photoreceptor degeneration and uncontrolled microglial activation and subretinal accumulation (Combadiere et al., 2007). Mononuclear cells with CX3CR1 deficiency express higher levels of CCL2 which leads to excessive recruitment and accumulation of neurotoxic subretinal macrophages. This process is known to be related to the development of age-related photoreceptor degeneration in mice (Sennlaub et al., 2013). Reduced levels or loss of CX3CR1 signaling in the aging retina may confer the neurotoxic phenotype of microglia, which may put the retina at risk of developing degenerative diseases.

\subsubsection{CD200-CD200R pathway in the aging retina}

CD200 is a $41-47 \mathrm{kDa}$ protein belonging to the immunoglobulin (Ig) supergene family (Barclay et al., 2002, Wright et al., 2001). CD200 is expressed throughout the retinal layers and its expression increases during inflammation, in both human and rat (Dick et al., 2001). CD200 is also constitutively expressed in the normal mouse retina, with high levels in the ganglion layer (GL) (Figure 3A). 
CD200R is detected at low levels in the ciliary body and inner retina, with a marked increase in EAU (Dick et al., 2001). Low levels of CD200R were also detected in the mouse retina (Figure 3B). Interestingly, RPE cells (Arrows in Figure 3B) and corneal epithelial cells also express CD200R (data not shown), suggesting that this pathway may also regulate epithelial activation. In the CNS and retina, the CD200-CD200R interaction is neuroprotective under inflammatory conditions (Hoek et al., 2000, Wright et al., 2000). Deletion of CD200 results in myeloid cell and microglial dysregulation and enhanced susceptibility to an autoimmune response (Hoek et al., 2000). Blocking the CD200CD200R signaling pathway aggravates inflammation in EAU (Banerjee and Dick, 2004, Broderick et al., 2002), whereas augmentation of the CD200R signaling suppresses inflammation and reduces tissue damage (Copland et al., 2007).

We have found that the mRNA expression of CD200 was significantly reduced in the aging (22 months) retina compared with that in the young (3 months) retina (Figure 3C). Retinal CD200R expression, however, did not change with age (Figure 3D). Previous work has reported an agemediated reduction in CD200 mRNA expression in the hippocampus of rats (Frank et al., 2006). Reduction in CD200 expression may weaken the inhibitory signal leading to increased microglial activation in the aging retina. Interestingly, CD200 expression in circulating CD11b monocytes of patients with neovascular age-related macular degeneration (nAMD) was reported to be increased compared to that in age-matched healthy controls (Singh et al., 2013). The biological significance of this observation in AMD pathogenesis remains elusive.

\subsubsection{CD47-SIRP (CD172) pathway in the aging retina}

CD47 and the signal regulatory protein (SIRP, also known as CD172) is another neuron-microglia ligand-receptor pathway that controls microglial response. CD47 is expressed by neurons, astrocytes, 
endothelial cells and various immune cells. SIRP (CD172) is expressed predominately by myeloidderived cells and microglia in the CNS (Barclay and Brown, 2006, Brown and Frazier, 2001). In the normal mouse retina, CD47 expression was found in the GL, inner plexiform layer (IPL) and outer plexiform layer (OPL) (Figure 3E). SIRP was diffusively expressed at low levels in the IPL, INL and OPL, although, high levels of expression were observed in some cells in the INL (arrowheads in Figure 3F). The SIRP family consists of SIRP $\alpha, \operatorname{SIRP} \beta$, and SIRP $\gamma$ as well as some other closely related proteins. In the brain, CD47 and SIRP can be co-expressed in the same cells and their interaction might mediate intracellular signaling in a bidirectional manner (Zhang et al., 2015). CD47SIRP interaction recruits the tyrosine phosphatases SHP-1 and SHP-2 leading to inhibition of phagocytosis and synthesis of the anti-inflammatory cytokine TGF- $\beta$ (Nimmerjahn et al., 2005). Surprisingly, despite the importance of the CD47-SIRP pathway in regulating CNS homeostasis and inflammation, little is known about their role in the CNS/retinal aging and age-related diseases. Using real-time RT-PCR, we did not observe any significant difference in the mRNA expression levels of CD47 (Figure 3G) and SIRP (Figure 3H) between young (3-months) and old (22-month) retinas.

Apart from SIRP, CD47 in immune cells partners with integrins such as CD11b and binds TSP-1, a secreted glycoprotein that plays an important role in inflammation and angiogenesis. The CD47/TSP1 interaction is known to induce the death of active T cells and suppress inflammation (Barclay and Van den Berg, 2014, Pettersen, 2000, Sarfati et al., 2008). A recent study has shown that the CD47/TSP-1 signaling pathway is important for the elimination of subretinal mononuclear phagocytes in the aging eye (Calippe et al., 2017). Disruption of the pathway, for example, by $\mathrm{CFH} / \mathrm{CD} 11 \mathrm{~b}-\mathrm{mediated}$ interaction, inhibits subretinal phagocyte elimination, which leads to retinal degeneration (Calippe et al., 2017). Further studies are required to understand the role of the 
CD47/SIRP/TSP-1 pathway in retinal aging and age-related retinal diseases.

\subsubsection{The endocannabinoid system in the aging retina}

Anandamide (arachidonoyl-ethanolamide, AEA) and 2-arachidonoyl-glycerol (2-AG) (both are endocannabinoids), cannabinoid receptors 1 and 2 (CB1 and CB2 receptors), as well as the enzymes that control endocannabinoids synthesis or degradation (FAAH, MGL, and COX2) have been detected in the retina, suggesting existence of the endocannabinoid system (Schwitzer et al., 2016, Yazulla, 2008). CB1 receptor is expressed in retinal neurons, Müller cells, and microglia (Straiker et al., 1999), whereas, the CB2 receptor is believed to be expressed predominately by microglia in the CNS (Lopez et al., 2011) and RPE cells in the retina (Wei et al., 2009). Activation of the CB1 and CB2 receptors in microglia induces an alternative activation phenotype (M2), which reduces inflammation (Mecha et al., 2016). Activation of the CB2 receptor using a selective agonist (JWH133) can suppress retinal inflammation in the mouse model of EAU through down-regulating TLR4/MyD88 expression (Xu, Cheng et al., 2007). In addition, the endocannabinoids or synthetic cannabinoids can alleviate the proinflammatory response in Müller cells (Krishnan and Chatterjee, 2012, Matias et al., 2006). The endocannabinoids-CB1/2 pathway is believed to be an important immune regulatory mechanism which controls inflammation in the CNS and the retina.

Previous studies have shown that the expression of CB1/CB2 receptors (Pascual, Gaveglio et al., 2014), the levels of bioavailable 2-AG and the enzyme activity of fatty acid amide hydrolase (FAAH) are reduced in the aging brain (Pascual et al., 2013, Pascual, Martin-Moreno et al., 2014). We have found that levels of 2-AG and AEA are increased with age in normal WT mouse retinas (Figure 4A, 4B). CCL2 KO mice have a significantly higher level of $2-A G$ at a younger age (3-month, Figure 4C), which decreases with age (Figure 4C). AEA levels in the CCL2 KO mouse retina, however, was 
significantly lower at 3- and 18-month of age compared with age-controlled WT mice (Figure 4D). Previously, we have shown that CCL2 KO mice age-dependently develop retinal degeneration, which is accompanied by increased microglial and complement activation (Chen et al., 2011). Dysregulated endocannabinoid expression may be related to uncontrolled microglial activation in CCL2 KO mice. High levels of AEA have been previously reported in the retina, ciliary body and choroid of eyes donated by patients with diabetic retinopathy (Matias et al., 2006). Interestingly, 2-AG was only increased in the iris of the DR eyes (Matias et al., 2006). High levels of AEA were also observed in the choroid of AMD eyes compared with controls, while the expression of 2-AG did not significantly change (Matias et al., 2006). However, the study did not consider age and other medical conditions of the donors, and the results should be interpreted with caution. Nevertheless, the endocannabinoid system is critically involved in retinal immune regulation, although, their role in age-mediated retinal para-inflammation and their contribution to age-related retinal degeneration requires further investigation.

\subsubsection{The impact of age on RPE immune regulation}

RPE cells maintain immune privilege status of the subretinal space by segregating the retina from choroidal circulation (through oBRB) and actively inhibiting immune activation (through expression of surface ligands and soluble molecules) (Kaestel et al., 2005, Zamiri et al., 2006, Zamiri et al., 2007). RPE-derived inhibitory cues can induce the death of active immune cells or convert them into immunosuppressive or regulatory cells (Kaestel et al., 2005, Mochizuki et al., 2013).

During aging, RPE cells undergo significant morphological and functional changes. RPE cell number declines (Friedman and Ts'o, 1968, Gao and Hollyfield, 1992) and their size increase (Chen et al., 2016), with many cells becoming binucleated or multinucleated (Chen et al., 2016, Friedman and Ts'o, 
1968). Their phagocytic and lysosomal activities also decrease with age (Wang et al., 2009), although the impact of age on their immune regulatory functions remains is unknown. Normal healthy RPE cells can upregulate the expression of IL-1 $\beta$, IL-6, arginase-1 and pentraxin 3 (PTX3) (Figure 5A, 5B), and down-regulate the expression of TNF $\alpha$ and IL-12 in macrophages (Figure 5A). Complement inhibitor C1INH expression in macrophages can also be significantly upregulated by RPE (Luo et al., 2018). Importantly, the ability of macrophages to phagocytose apoptotic $\mathrm{T}$ cells is significantly increased after co-culturing with RPE cells (Figure 6A-C, E). The results suggest that under normal physiological conditions, RPE cells are able to modulate macrophage phenotype and function and promote their ability to remove debris.

When RPE cells were pre-treated with oxidized photoreceptor outer segments (oxPOS), they became multinucleated (Chen et al., 2016, Rajapakse et al., 2017) and acquired a senescent phenotype. This was evident by the upregulation of senescence-associated genes (Apo J, fibronectin, SM22, and osteonectin) (Lueck et al., 2012) and $\beta$-galactosidase expression (Luo et al., 2018). The oxPOSinduced senescent RPE cells expressed higher levels of inflammatory mediators such as complement factor B (CFB) (Chen et al., 2008), IL-1 $\beta$, IL-6, IL-8, CCL2 (Higgins et al., 2003) and VEGF (Lueck et al., 2012). Our recent study suggests that oxPOS induces expression of the cell cycle inhibitor P27Kip1 in RPE cells (Rajapakse et al., 2017), which may further explain their senescent phenotype. Macrophages co-cultured with the senescent RPE cells expressed higher levels of IL-1 $\beta$, and IL-6 (Figure 5A), but lower levels of arginase-1 and PTX3 (Figure 5B), compared to macrophages cocultured with normal RPE, indicating a shift towards an inflammatory phenotype. The senescent RPE cells maintain the ability to promote macrophage phagocytic function. Macrophages pre-treated with the senescent RPE phagocytosed the same amount of apoptotic T cells compared to macrophages pre- 
treated with normal RPE cells (Figure 6C, 6D, 6E). Taken together, the results suggest that senescent RPE cells maintain immune regulatory roles, but with reduced ability.

\subsection{The impact of age on retinal immune effectors}

The retinal immune effectors include innate immune cells (e.g., microglia, perivascular macrophages and dendritic cells (Chen and $\mathrm{Xu}, 2015$, Forrester et al., 2010, Xu, Dawson et al., 2007) and the complement system (Xu and Chen, 2016). Here we discuss the impact of age on retinal microglia and the complement system due to their recognised roles in age-related retinal degenerative and angiogenic diseases. Circulating monocytes may infiltrate the aging retina via the fragile physical barriers (iBRB and $\mathrm{oBRB}$ ) and differentiate into microglia-like cells which participate in retinal defence. Direct evidence supporting the existence of infiltrating macrophage in the normal aging retina is lacking. Therefore, the topic is not discussed further in this review.

\subsubsection{Altered microglial response in the aging retina}

\subsubsection{Microglial functional alterations in the aging retina}

Apart from the age-related changes in the regulatory cues from neurons, astrocytes, Müller cells, and RPE cells, retinal microglia also present age-related alterations. Under normal physiological conditions, microglia patrol the surrounding microenvironment using their highly motile dendrites (Figure 7A). The mobility of microglial dendrites reduces with age (Damani et al., 2011). In response to injury, aged microglia migrate to the site of damage slower than young microglia (Damani et al., 2011, Ma and Wong, 2016). After resolving inflammation and damage repair, aged microglia disperse from the damaged site slower than young microglia (Damani et al., 2011, Ma and Wong, 2016). Aging microglia also appear to have increased immune vigilance (Deczkowska et al., 2017) with 
dysregulated phagocytic activity (Grabert et al., 2016, Hickman et al., 2013). For example, aged microglia may phagocytize living neurons (Zhao et al., 2015) or engage in excessive synaptic pruning through complement component 1q (C1q) leading to the damage of synaptic connections (Lui et al., 2016, Morrison and Baxter, 2012). Aged microglia also display insufficient phagocytic activity towards apoptotic bodies, protein aggregates and myelin, resulting in the gradual accumulation of potentially toxic compounds which is a hallmark of age-related neurodegenerative diseases (Safaiyan et al., 2016). Furthermore, their plasticity to change from a pro-inflammatory to an anti-inflammatory phenotype is also reduced with age (Harry, 2013). The underlying mechanism which leads to these functional changes in senescent microglia is not fully understood. One explanation could be an intrinsic dysfunction of microglia resulting from age (see below). Accumulation of oxidative insults in the aging brain and retinal microenvironment may increase the workload of microglia, while the changes in retinal metabolism during aging may affect the response of microglia to oxidative insults. Furthermore, the reduced regulatory cues from neurons may also contribute to a dysregulated microglia response in the aging retina (Figure 7B).

\subsubsection{Transcriptomic changes in aging microglia}

A recent transcriptomic analysis of human cortical microglia revealed age-related reductions in the expression of genes involved in the actin cytoskeleton system (e.g., TLN1, PFN1 EVL, ARPC1A, etc.), sensome cell surface receptors (e.g., P2RY12, IL6R, TLR10) and adhesion molecules (e.g., ICAM3, ROBO2) (Galatro et al., 2017). These transcriptional changes may explain the age-related alterations in microglial functions (i.e. phagocytosis, migration, immune response etc.). Moreover, a genomewide analysis of microglia from mouse brain has reported region-specific microglial transcriptional identities and heterogeneous microglial aging in different regions (Grabert et al., 2016). One study 
showed that aging caused a modest decline in the expression of key signature genes of microglia across all forebrain regions, with a significantly greater reduction in cerebellar microglia (Grabert et al., 2016). The authors suggested that microglial diversity may enable localized homeostatic functions which would underlie region-specific sensitivities to microglial dysregulation and the involvement in age-related neurodegeneration (Grabert et al., 2016). Retinal microglia are distributed in different layers (GL, IPL and OPL) (Chen and Xu, 2015, Karlstetter et al., 2015) and different regions (e.g., macula and periphery) of the retina. Dysregulated microglial activation is known to be involved in all types of age-related retinal degenerative diseases (AMD, DR, glaucomatous retinopathy, retinitis pigmentosa etc.), with each disease affecting different layers/regions of the retina. Whether a regional- or layer-specific microglial aging exists in the retina remains to be clarified.

\subsubsection{Age-related metabolic alteration and retinal microglial activation}

Cells metabolize glucose, fatty acids or amino acids to generate ATP and other biomaterials to support cellular function. Immune cell activation is critically controlled by metabolic pathways (Kelly and O'Neill, 2015, Pearce et al., 2013). For example, quiescent and alternatively activated M2 macrophages and microglia are fueled by mitochondrial oxidative phosphorylation (OXPHOS), whereas proinflammatory M1 macrophages and microglia rely on glycolysis to function (Kelly and O'Neill, 2015, Orihuela et al., 2016, Pearce et al., 2013). Although retina consumes high levels of oxygen (per gram tissue compared to other tissues) for function, the oxygen tension, particularly in the outer layers of the retina is extremely low (approximately $5 \mathrm{mmHg}$ ) (Yu and Cringle, 2001). With age, retinal oxygen supply further decreases due to reduced permeability of Bruch's membrane and vascular basal membrane and accumulation of drusen deposits (Stefansson et al., 2011). Thus, the aging retina suffers from low-grade chronic ischemia. It is unclear how age affects the supply of 
retinal nutrients (e.g. glucose and fatty acids) as the ischemic condition will likely impair mitochondrial respiration. A recent study has shown that glucose and amino acid metabolism is significantly altered in the aging retina (Wang et al., 2018). Oxaloacetate, a critical metabolite in the TCA cycle and the malate-aspartate shuttle, were significantly reduced. Metabolites from glycolysis and mitochondrial OXPHOS were diminished by a half in old mouse retinas (73 weeks old) as compared with young retinas (6 weeks old), indicating the impairment of glucose utilization (Wang et al., 2018). Microglial activation is likely to be affected by the impaired glycolysis and mitochondrial OXPHOS in the aging retina.

Macrophages and microglia are specialized in metabolizing fatty acids, an essential function for eliminating cholesterols that they acquire through phagocytosis of dead cells. Cholesterol metabolism and mitochondrial OXPHOS are impaired in aged macrophages (Lin et al., 2018), leading to intracellular accumulation of oxidized cholesterols (Lin et al., 2018). Subretinal mononuclear phagocytes in the aging eye contain large amounts of autofluorescent lipofuscins (Luhmann et al., 2009, Xu et al., 2008), which may result from undigested fatty acids. Free fatty acids (e.g. cholesterol) can bind to and activate several transcription factors, including liver X receptor $\alpha$ and $\beta$ (LXR $\alpha$ and $\mathrm{LXR} \beta)$, retinoid $\mathrm{X}$ receptor (RXR) and members of the peroxisome proliferator-activated receptor (PPAR) family (PPAR $\alpha$ and PPAR $\gamma$ ), resulting in inflammatory gene expression (Remmerie and Scott, 2018). Dysregulated cholesterol metabolism in aged macrophages may underlie their inflammatory phenotype. Further studies will be necessary to understand how microglial activation in the aging retina is regulated by metabolic changes.

\subsubsection{Altered complement response in the aging retina}

Previously, we and others have shown that the retina has a complement regulatory system (Chen and 
$\mathrm{Xu}, 2015$, Xu et al., 2009, Xu and Chen, 2016) and retinal cells, in particular microglia and RPE cells can produce various complement proteins and regulators (Anderson et al., 2010, Luo et al., 2011). Under normal physiological conditions, retinal cells express relatively higher levels of complement regulators (e.g., $\mathrm{CFH}, \mathrm{C} 1 \mathrm{INH}$, and $\mathrm{CD} 59$ ) and lower levels of complement proteins (e.g. C1q, C3, and CFB) (Anderson et al., 2010, Xu et al., 2009) (Figure 8A). Complement expression has been shown to increase in the aging retina (Anderson et al., 2010, Chen et al., 2008, Xu et al., 2009), meaning the complement system may be active in the retinal immune defense against aging insults. Complement proteins such as $\mathrm{C} 1 \mathrm{q}$ and the $\mathrm{C} 3$ fragment $\mathrm{C} 3 \mathrm{~b}$ can opsonize debris and dead cells, as a result promoting their clearance by phagocytes (He et al., 2008, Mevorach et al., 1998, Takizawa et al., 1996).

In the aging retina, the expression of complement regulators is generally down-regulated, whereas the expression of complement proteins is up-regulated (Figure $8 \mathrm{~B}$ ). This may be caused by multiple mechanisms. On the one hand, age-related oxidative insults can directly modulate complement expression in retinal cells. For example, oxPOS can reduce the expression of complement inhibitor CFH (Chen et al., 2007) but increase the expression of CFB in RPE cells (Chen et al., 2008). On the other hand, the immune suppressive microenvironment is altered during aging, which potentially disrupts the production of various complement regulators (C4bp, C1INH, DAF and CD59) by RPE and microglia (Luo et al., 2011, Luo et al., 2013). RPE cells can promote the expression of complement regulators in macrophage (Luo et al., 2018), but this ability is reduced when RPE undergoes senescence (Luo et al., 2018). Furthermore, inflammatory cytokines released by subretinal macrophages may upregulate the expression of complement proteins and down-regulate the expression of complement regulators in RPE cells (Luo et al., 2011) (Figure 8B). 


\subsection{Age-related changes in intraocular compartment mediated systemic immune regulation}

Once the antigens breach the ocular barriers and reach the immune privileged compartments such as the anterior chamber, vitreous cavity and subretinal space, they can induce antigen-specific immune tolerance (e.g. ACAID and VCAID) to minimize ocular immunopathology (Jiang et al., 1993, Streilein, 1995). A previous study has found that aged C57BL/6 mice and Royal College of Surgeon (RCS) rats both maintain ACAID. However, ACAID cannot be induced in aged $\mathrm{rd} / \mathrm{rd}$ mice, where the photoreceptors are degenerated (Welge-Lussen et al., 1999). The loss of ACAID in aged rd/rd mice is known to be associated with lower levels of TGF $\beta 2$ in the aqueous humour (Welge-Lussen et al., 1999).

Hyalocytes are the resident immune cells in the vitreous cavity and their density is increased in aged mice (Vagaja et al., 2012). Immune cells are normally absent in the subretinal space, however, microglia and macrophages migrate there with age (Combadiere et al., 2007, Raoul, Feumi et al., 2008, Xu et al., 2008). An increased number of hyalocytes and accumulation of subretinal phagocytes would undoubtedly affect immune regulation in the vitreous cavity and the subretinal space. Whether aging directly affects the immune deviation remains unclear. Previous studies have shown that retinal laser burn-induced neuropathy can lead to loss of ACAID (Qiao et al., 2009) through upregulation of substance P (Lucas et al., 2012). The results suggest that the systemic immune regulatory function of the eye may be lost in patients with retinal neuropathy. This would subsequently have implications in the pathogenesis of various retinal diseases. Impaired or lost ocular chamber-induced immune deviation in AMD, DR or glaucoma could initiate a retinal antigen-specific $\mathrm{T}$ or B cell response when retinal antigens are released into the ocular chamber from dead cells. Indeed, autoantibodies have been detected in AMD (Cherepanoff et al., 2006, Gu et al., 2003), DR (Ahn et al., 2006) and glaucoma 
(Tezel et al., 1999, Tezel et al., 2004, Wax, Yang et al., 2001, Wax, Tezel et al., 2001). The autoimmunity response, despite at low levels, may further damage the neuronal retina. A recent study has shown that transient elevation of intraocular pressure induces heat shock protein (HSP)-specific $\mathrm{T}$ cell infiltration and sustained ganglion cell degeneration in glaucomatous mice and human glaucoma patients (Chen et al., 2018). The development of retinal autoantibodies or CD4 T cells in these patients may be related to loss of ocular chamber-induced immune deviation.

\section{The impact of systemic inflammation in the aging retina}

A low level of peripheral systemic inflammation can induce neuroinflammation, which may increase the susceptibility of neuronal degeneration. A previous study has shown that intraperitoneal injection of LPS induced brain microglial activation and increased production of pro-inflammatory cytokines (i.e. TNF $\alpha$ and IL-1 $\beta$ ) (Xie et al., 2017). Depletion of circulating monocytes or blocking the CD200CD200R pathway attenuated peripheral LPS-induced CNS inflammation (Xie et al., 2017). The results suggest that peripheral inflammation can be transmitted into the CNS. In the eye, it is well known that peripheral LPS stimulation induces intraocular inflammation (uveitis) (Rosenbaum et al., 1980). Furthermore, intraperitoneal injection of LPS (Vagaja et al., 2012) or topical application of TLR9 or TLR7/8 agonists can induce low-levels of retinal inflammation including, increased hyalocyte density (Vagaja et al., 2012) and subretinal accumulation of activated microglia (Chinnery et al., 2011, Chinnery et al., 2015), suggesting that peripheral inflammation may also be transmitted into the retina, although, the underlying mechanism remains elusive.

Circulating immune cells and inflammatory mediators including complement proteins may gain 
access to the retina through the choroid. The wall of the choriocapillaris facing Bruch's membrane is fenestrated with approximately $800 \AA$ circular openings, which allow easy movement of macromolecules into the extra-capillary compartment (Anand-Apte, 2010). During systemic inflammation, such as infection, pathogens and inflammatory mediators (e.g. complement proteins, chemokines and cytokines) can escape from leaky vessels and percolate through Bruch's membrane to the basal side of the RPE leading to re-structuring of tight junctions and breakdown of the oBRB. Access of peripheral pathogens or circulating inflammatory molecules to the neuroretina may become easier in the aging eye due to weak BRBs (Section 3.1 Figure 2A). Recent discovery of intraocular microbiota in the aqueous humor of uveitis patients and soft drusen of AMD patients (Wen et al., 2018) suggests that the retina is not totally insulated from the peripheral circulation.

Aging is associated with low-levels of systemic inflammation (inflammaging) (Franceschi and Campisi, 2014, Goto, 2008) and infections occur frequently in aged people due to immune senescence. It is possible that systemic inflammation, particularly from acute infection in old people may cause low-levels of retinal inflammation, which may negatively impact on retinal immune privilege.

\section{Conclusions and therapeutic implications}

With age, the three layers of protection that maintains retinal immune privilege undergo substantial changes. Physical barriers, including the iBRB and oBRB appear to be weakened due to age-related dysfunction of endothelial and glial cells in the neurovascular unit and RPE (Table 1). Immune regulatory signals from retinal neurons or RPE cells are also altered. CX3CL1 and CD200 expression in neurons is reduced, whereas, the production of endocannabinoid 2-AG and AEA is increased in the 
aging retina. The ocular chamber-mediated systemic immune suppression (deviation) may be lost during aging due to reduced TGF $\beta$ expression and immune cell infiltration into the chamber (Table 1). Reduction in passive protection (i.e. avoidance and tolerance) makes the retina more susceptible to insults such as oxidative stress in AMD, hyperglycemia in diabetes and elevated intraocular pressure in glaucoma.

The immune effectors (i.e. microglia and the complement system) that safeguard the retina also undergo significant age-related changes. Age reduces the mobility of microglia, which causes their phagocytic function to decline as well as their shift to a proinflammatory phenotype when responding to danger molecules. In addition, the expression of complement inhibitors is reduced, and the expression of complement activators is increased in the aging retina (Table 1). Therefore, on the one hand, aged microglia have a reduced ability to carry out their immune surveillance and synapse maintenance roles, leading to accumulation of damaged neurons and debris. On the other hand, the proinflammatory response of microglia and the complement system to damaged neurons and debris increases the immunopathology.

In the degenerative retina (e.g. AMD and DR), barriers may be damaged at the lesion site and immune suppressive pathways could be altered or lost (Table 1). However, patients can remain asymptomatic for years at the early stages of the disease, suggesting that avoidance and tolerance strategies are still functioning sufficiently to keep the retina privileged or partially privileged from systemic immune attack. The defense system (e.g. retinal microglia and the complement system) is likely to be activated constantly at low levels in the diseased retina due to an increase in tissue damage from aging or diabetes (Table 1). Improving the defense and tolerance mechanisms to maintain or restore retinal immune privilege in the aging and degenerative retina would be a preferred approach for disease 
retardation or prevention.

Intraocular drug delivery is a well-accepted and widely-used approach for treating retinal diseases. Cell-based therapies have shown promising effects in preclinical studies and phase $1 / 2$ clinical trials for end-stage AMD patients (Jones et al., 2017). The altered immune privilege of the aging and degenerative retina may negatively affect the materials (e.g. cells, drug carriers and genes) that are delivered into the vitreous cavity or subretinal space. Thorough studies on the impact of retinal immune response to the materials may help to improve the efficacy and success rate of intraocular drug, gene and cell therapy.

\section{Acknowledgements}

The work was funded by Fight for Sight (1361/1362; 1425/1426; 1574/1574; 5057/58), Dunhill Medical Trust (R188/0211), and National Eye Research Center (SCIAD 061). The authors would like to thank Kevin Harkin for helping with English expression. 


\section{References}

Ahn, B.Y., Song, E.S., Cho, Y.J., Kwon, O.W., Kim, J.K., Lee, N.G., 2006. Identification of an anti-aldolase autoantibody as a diagnostic marker for diabetic retinopathy by immunoproteomic analysis. Proteomics. 6, 1200-1209.

Anand-Apte, B.H.,J.G., 2010. Developmental Anatomy of the Retinal and Choroidal Vasculature. Encyclopedia of the Eye, 9-15.

Anderson, D.H., Radeke, M.J., Gallo, N.B., Chapin, E.A., Johnson, P.T., Curletti, C.R., Hancox, L.S., Hu, J., Ebright, J.N., Malek, G., Hauser, M.A., Rickman, C.B., Bok, D., Hageman, G.S., Johnson, L.V., 2010. The pivotal role of the complement system in aging and age-related macular degeneration: hypothesis re-visited. Prog.Retin.Eye Res. 29, 95-112.

Ardeljan, D., Chan, C.C., 2013. Aging is not a disease: distinguishing age-related macular degeneration from aging. Prog.Retin.Eye Res. 37, 68-89.

Banerjee, D., Dick, A.D., 2004. Blocking CD200-CD200 receptor axis augments NOS-2 expression and aggravates experimental autoimmune uveoretinitis in Lewis rats. Ocul.Immunol.Inflamm. 12, 115-125.

Barclay, A.N., Brown, M.H., 2006. The SIRP family of receptors and immune regulation. Nat.Rev.Immunol. 6, 457-464.

Barclay, A.N., Van den Berg, T.K., 2014. The interaction between signal regulatory protein alpha (SIRPalpha) and CD47: structure, function, and therapeutic target. Annu.Rev.Immunol. 32, 25-50.

Barclay, A.N., Wright, G.J., Brooke, G., Brown, M.H., 2002. CD200 and membrane protein interactions in the control of myeloid cells. Trends Immunol. 23, 285-290.

Battista, N., Fezza, F., Finazzi-Agro, A., Maccarrone, M., 2006. The endocannabinoid system in neurodegeneration. Ital.J.Biochem. 55, 283-289.

Broderick, C., Hoek, R.M., Forrester, J.V., Liversidge, J., Sedgwick, J.D., Dick, A.D., 2002. Constitutive Retinal CD200 Expression Regulates Resident Microglia and Activation State of Inflammatory Cells during Experimental Autoimmune Uveoretinitis. Am.J.Pathol. 161, 1669-1677.

Brown, E.J., Frazier, W.A., 2001. Integrin-associated protein (CD47) and its ligands. Trends Cell Biol. 11, 130-135.

Calippe, B., Augustin, S., Beguier, F., Charles-Messance, H., Poupel, L., Conart, J.B., Hu, S.J., Lavalette, S., Fauvet, A., Rayes, J., Levy, O., Raoul, W., Fitting, C., Denefle, T., Pickering, M.C., Harris, C., Jorieux, S., Sullivan, P.M., Sahel, J.A., Karoyan, P., Sapieha, P., Guillonneau, X., Gautier, E.L., Sennlaub, F., 2017. Complement Factor H Inhibits CD47-Mediated Resolution of Inflammation. Immunity. 46, 261-272. 
Cardona, A.E., Pioro, E.P., Sasse, M.E., Kostenko, V., Cardona, S.M., Dijkstra, I.M., Huang, D., Kidd, G., Dombrowski, S., Dutta, R., Lee, J.C., Cook, D.N., Jung, S., Lira, S.A., Littman, D.R., Ransohoff, R.M., 2006. Control of microglial neurotoxicity by the fractalkine receptor.

Nat.Neurosci. 9, 917-924.

Cardona, S.M., Mendiola, A.S., Yang, Y.C., Adkins, S.L., Torres, V., Cardona, A.E., 2015. Disruption of Fractalkine Signaling Leads to Microglial Activation and Neuronal Damage in the Diabetic Retina. ASN Neuro. 7, 10.1177/1759091415608204. Print 2015 Sep-Oct.

Caspi, R.R., 2006. Ocular autoimmunity: the price of privilege?. Immunol.Rev. 213, 23-35.

Caspi, R.R., Roberge, F.G., McAllister, C.G., el Saied, M., Kuwabara, T., Gery, I., Hanna, E., Nussenblatt, R.B., 1986. T cell lines mediating experimental autoimmune uveoretinitis (EAU) in the rat. J.Immunol. 136, 928-933.

Chan, C.C., Mochizuki, M., Palestine, A.G., BenEzra, D., Gery, I., Nussenblatt, R.B., 1985.

Kinetics of T-lymphocyte subsets in the eyes of Lewis rats with experimental autoimmune uveitis. Cell.Immunol. 96, 430-434.

Chan-Ling, T., Hughes, S., Baxter, L., Rosinova, E., McGregor, I., Morcos, Y., van Nieuwenhuyzen, P., Hu, P., 2007. Inflammation and breakdown of the blood-retinal barrier during "physiological aging" in the rat retina: a model for CNS aging. Microcirculation. 14, 63-76.

Chen, H., Cho, K.S., Vu, T.H.K., Shen, C.H., Kaur, M., Chen, G., Mathew, R., McHam, M.L., Fazelat, A., Lashkari, K., Au, N.P.B., Tse, J.K.Y., Li, Y., Yu, H., Yang, L., Stein-Streilein, J., Ma, C.H.E., Woolf, C.J., Whary, M.T., Jager, M.J., Fox, J.G., Chen, J., Chen, D.F., 2018. Commensal microflora-induced $\mathrm{T}$ cell responses mediate progressive neurodegeneration in glaucoma. Nat.Commun. 9, 3209-018-05681-9.

Chen, M., Forrester, J.V., Xu, H., 2011. Dysregulation in retinal para-inflammation and age-related retinal degeneration in CCL2 or CCR2 deficient mice. PLoS One. 6, e22818.

Chen, M., Forrester, J.V., Xu, H., 2007. Synthesis of complement factor H by retinal pigment epithelial cells is down-regulated by oxidized photoreceptor outer segments. Exp.Eye Res. 84, 635645.

Chen, M., Hombrebueno, J.R., Luo, C., Penalva, R., Zhao, J., Colhoun, L., Pandi, S.P., Forrester, J.V., Xu, H., 2013. Age- and Light-Dependent Development of Localised Retinal Atrophy in CCL2(-/-)CX3CR1(GFP/GFP) Mice. PLoS One. 8, e61381.

Chen, M., Luo, C., Penalva, R., Xu, H., 2013. Paraquat-Induced Retinal Degeneration Is Exaggerated in CX3CR1-Deficient Mice and Is Associated with Increased Retinal Inflammation. Invest.Ophthalmol.Vis.Sci. 54, 682-690.

Chen, M., Muckersie, E., Forrester, J.V., Xu, H., 2010. Immune activation in Retinal Aging: A Gene Expression Study. Invest.Ophthalmol.Vis.Sci. 51, 5888-5896. 
Chen, M., Muckersie, E., Robertson, M., Forrester, J.V., Xu, H., 2008. Up-regulation of complement factor $\mathrm{B}$ in retinal pigment epithelial cells is accompanied by complement activation in the aged retina. Exp.Eye Res. 87, 543-550.

Chen, M., Rajapakse, D., Fraczek, M., Luo, C., Forrester, J.V., Xu, H., 2016. Retinal pigment epithelial cell multinucleation in the aging eye - a mechanism to repair damage and maintain homoeostasis. Aging Cell.

Chen, M., Xu, H., 2015. Parainflammation, chronic inflammation, and age-related macular degeneration. J.Leukoc.Biol. 98, 713-725.

Cherepanoff, S., Mitchell, P., Wang, J.J., Gillies, M.C., 2006. Retinal autoantibody profile in early age-related macular degeneration: preliminary findings from the Blue Mountains Eye Study. Clin.Experiment.Ophthalmol. 34, 590-595.

Chinnery, H.R., McLenachan, S., Humphries, T., Kezic, J.M., Chen, X., Ruitenberg, M.J., McMenamin, P.G., 2011. Accumulation of murine subretinal macrophages: effects of age, pigmentation and CX(3)CR1. Neurobiol.Aging. 33, 1769-1776.

Chinnery, H.R., Naranjo Golborne, C., Leong, C.M., Chen, W., Forrester, J.V., McMenamin, P.G., 2015. Retinal Microglial Activation Following Topical Application of Intracellular Toll-Like Receptor Ligands. Invest.Ophthalmol.Vis.Sci. 56, 7377-7386.

Colonna, M., 2003. TREMs in the immune system and beyond. Nat.Rev.Immunol. 3, 445-453.

Combadiere, C., Feumi, C., Raoul, W., Keller, N., Rodero, M., Pezard, A., Lavalette, S., Houssier, M., Jonet, L., Picard, E., Debre, P., Sirinyan, M., Deterre, P., Ferroukhi, T., Cohen, S.Y., Chauvaud, D., Jeanny, J.C., Chemtob, S., Behar-Cohen, F., Sennlaub, F., 2007. CX3CR1-dependent subretinal microglia cell accumulation is associated with cardinal features of age-related macular degeneration. J.Clin.Invest. 117, 2920-2928.

Copland, D.A., Calder, C.J., Raveney, B.J., Nicholson, L.B., Phillips, J., Cherwinski, H., Jenmalm, M., Sedgwick, J.D., Dick, A.D., 2007. Monoclonal antibody-mediated CD200 receptor signaling suppresses macrophage activation and tissue damage in experimental autoimmune uveoretinitis. Am.J.Pathol. 171, 580-588.

Damani, M.R., Zhao, L., Fontainhas, A.M., Amaral, J., Fariss, R.N., Wong, W.T., 2011. Agerelated alterations in the dynamic behavior of microglia. Aging Cell. 10, 263-276.

De Simone, R., Ambrosini, E., Carnevale, D., Ajmone-Cat, M.A., Minghetti, L., 2007. NGF promotes microglial migration through the activation of its high affinity receptor: modulation by TGF-beta. J.Neuroimmunol. 190, 53-60.

Deczkowska, A., Matcovitch-Natan, O., Tsitsou-Kampeli, A., Ben-Hamo, S., Dvir-Szternfeld, R., Spinrad, A., Singer, O., David, E., Winter, D.R., Smith, L.K., Kertser, A., Baruch, K., Rosenzweig, N., Terem, A., Prinz, M., Villeda, S., Citri, A., Amit, I., Schwartz, M., 2017. Mef2C restrains 
microglial inflammatory response and is lost in brain ageing in an IFN-I-dependent manner. Nat.Commun. 8, 717-017-00769-0.

Dick, A.D., Broderick, C., Forrester, J.V., Wright, G.J., 2001. Distribution of OX2 antigen and OX2 receptor within retina. Invest.Ophthalmol.Vis.Sci. 42, 170-176.

Dick, A.D., Carter, D., Robertson, M., Broderick, C., Hughes, E., Forrester, J.V., Liversidge, J., 2003. Control of myeloid activity during retinal inflammation. J.Leukoc.Biol. 74, 161-166.

Egan, R.M., Yorkey, C., Black, R., Loh, W.K., Stevens, J.L., Woodward, J.G., 1996. Peptidespecific $\mathrm{T}$ cell clonal expansion in vivo following immunization in the eye, an immune-privileged site. J.Immunol. 157, 2262-2271.

Ferguson, T.A., Griffith, T.S., 2007. The role of Fas ligand and TNF-related apoptosis-inducing ligand (TRAIL) in the ocular immune response. Chem.Immunol.Allergy. 92, 140-154.

Ferguson, T.A., Griffith, T.S., 1997. A vision of cell death: insights into immune privilege. Immunol.Rev. 156, 167-184.

Forrester, J.V., Xu, H., 2012. Good news-bad news: the Yin and Yang of immune privilege in the eye. Front.Immunol. 3, 338.

Forrester, J.V., Xu, H., Kuffova, L., Dick, A.D., McMenamin, P.G., 2010. Dendritic cell physiology and function in the eye. Immunol.Rev. 234, 282-304.

Franceschi, C., Campisi, J., 2014. Chronic inflammation (inflammaging) and its potential contribution to age-associated diseases. J.Gerontol.A Biol.Sci.Med.Sci. 69 Suppl 1, S4-9.

Frank, M.G., Barrientos, R.M., Biedenkapp, J.C., Rudy, J.W., Watkins, L.R., Maier, S.F., 2006. mRNA up-regulation of MHC II and pivotal pro-inflammatory genes in normal brain aging. Neurobiol.Aging. 27, 717-722.

Friedman, E., Ts'o, M.O., 1968. The retinal pigment epithelium. II. Histologic changes associated with age. Arch.Ophthalmol. 79, 315-320.

Galatro, T.F., Holtman, I.R., Lerario, A.M., Vainchtein, I.D., Brouwer, N., Sola, P.R., Veras, M.M., Pereira, T.F., Leite, R.E.P., Moller, T., Wes, P.D., Sogayar, M.C., Laman, J.D., den Dunnen, W., Pasqualucci, C.A., Oba-Shinjo, S.M., Boddeke, E.W.G.M., Marie, S.K.N., Eggen, B.J.L., 2017. Transcriptomic analysis of purified human cortical microglia reveals age-associated changes. Nat.Neurosci. 20, 1162-1171.

Gao, H., Hollyfield, J.G., 1992. Aging of the human retina. Differential loss of neurons and retinal pigment epithelial cells. Invest.Ophthalmol.Vis.Sci. 33, 1-17.

Goto, M., 2008. Inflammaging (inflammation + aging): A driving force for human aging based on an evolutionarily antagonistic pleiotropy theory?. Biosci.Trends. 2, 218-230. 
Grabert, K., Michoel, T., Karavolos, M.H., Clohisey, S., Baillie, J.K., Stevens, M.P., Freeman, T.C., Summers, K.M., McColl, B.W., 2016. Microglial brain region-dependent diversity and selective regional sensitivities to aging. Nat.Neurosci. 19, 504-516.

Gregerson, D.S., 1998. Immune privilege in the retina. Ocul.Immunol.Inflamm. 6, 257-267.

Gu, X., Meer, S.G., Miyagi, M., Rayborn, M.E., Hollyfield, J.G., Crabb, J.W., Salomon, R.G., 2003. Carboxyethylpyrrole protein adducts and autoantibodies, biomarkers for age-related macular degeneration. J.Biol.Chem. 278, 42027-42035.

Gupta, R.K., Prasad, S., 2013. Early down regulation of the glial Kir4.1 and GLT-1 expression in pericontusional cortex of the old male mice subjected to traumatic brain injury. Biogerontology. 14, 531-541.

Harrison, J.K., Jiang, Y., Chen, S., Xia, Y., Maciejewski, D., McNamara, R.K., Streit, W.J., Salafranca, M.N., Adhikari, S., Thompson, D.A., Botti, P., Bacon, K.B., Feng, L., 1998. Role for neuronally derived fractalkine in mediating interactions between neurons and CX3CR1-expressing microglia. Proc.Natl.Acad.Sci.U.S.A. 95, 10896-10901.

Harry, G.J., 2013. Microglia during development and aging. Pharmacol.Ther. 139, 313-326.

He, J.Q., Wiesmann, C., van Lookeren Campagne, M., 2008. A role of macrophage complement receptor CRIg in immune clearance and inflammation. Mol.Immunol. 45, 4041-4047.

Helming, L., Tomasello, E., Kyriakides, T.R., Martinez, F.O., Takai, T., Gordon, S., Vivier, E., 2008. Essential role of DAP12 signaling in macrophage programming into a fusion-competent state. Sci.Signal. 1, ra11.

Hernangomez, M., Carrillo-Salinas, F.J., Mecha, M., Correa, F., Mestre, L., Loria, F., Feliu, A., Docagne, F., Guaza, C., 2014. Brain innate immunity in the regulation of neuroinflammation: therapeutic strategies by modulating CD200-CD200R interaction involve the cannabinoid system. Curr.Pharm.Des. 20, 4707-4722.

Hickman, S.E., El Khoury, J., 2014. TREM2 and the neuroimmunology of Alzheimer's disease. Biochem.Pharmacol. 88, 495-498.

Hickman, S.E., Kingery, N.D., Ohsumi, T.K., Borowsky, M.L., Wang, L.C., Means, T.K., El Khoury, J., 2013. The microglial sensome revealed by direct RNA sequencing. Nat.Neurosci. 16, 1896-1905.

Higgins, G.T., Wang, J.H., Dockery, P., Cleary, P.E., Redmond, H.P., 2003. Induction of angiogenic cytokine expression in cultured RPE by ingestion of oxidized photoreceptor outer segments. Invest.Ophthalmol.Vis.Sci. 44, 1775-1782. 
Hoek, R.M., Ruuls, S.R., Murphy, C.A., Wright, G.J., Goddard, R., Zurawski, S.M., Blom, B., Homola, M.E., Streit, W.J., Brown, M.H., Barclay, A.N., Sedgwick, J.D., 2000. Down-regulation of the macrophage lineage through interaction with OX2 (CD200). Science. 290, 1768-1771.

Horie, S., Sugita, S., Futagami, Y., Yamada, Y., Mochizuki, M., 2010. Human retinal pigment epithelium-induced CD4+CD25+ regulatory T cells suppress activation of intraocular effector T cells. Clin.Immunol. 136, 83-95.

Hu, S.J., Calippe, B., Lavalette, S., Roubeix, C., Montassar, F., Housset, M., Levy, O., Delarasse, C., Paques, M., Sahel, J.A., Sennlaub, F., Guillonneau, X., 2015. Upregulation of P2RX7 in Cx3cr1-Deficient Mononuclear Phagocytes Leads to Increased Interleukin-1beta Secretion and Photoreceptor Neurodegeneration. J.Neurosci. 35, 6987-6996.

Hughes, S., Gardiner, T., Hu, P., Baxter, L., Rosinova, E., Chan-Ling, T., 2006. Altered pericyteendothelial relations in the rat retina during aging: implications for vessel stability. Neurobiol.Aging. 27, 1838-1847.

Jiang, L.Q., Jorquera, M., Streilein, J.W., 1993. Subretinal space and vitreous cavity as immunologically privileged sites for retinal allografts. Invest.Ophthalmol.Vis.Sci. 34, 3347-3354.

Jones, M.K., Lu, B., Girman, S., Wang, S., 2017. Cell-based therapeutic strategies for replacement and preservation in retinal degenerative diseases. Prog.Retin.Eye Res. 58, 1-27.

Kaestel, C.G., Lovato, P., Odum, N., Nissen, M.H., Ropke, C., 2005. The immune privilege of the eye: human retinal pigment epithelial cells selectively modulate $\mathrm{T}$-cell activation in vitro. Curr.Eye Res. 30, 375-383.

Karlstetter, M., Scholz, R., Rutar, M., Wong, W.T., Provis, J.M., Langmann, T., 2015. Retinal microglia: just bystander or target for therapy?. Prog.Retin.Eye Res. 45, 30-57.

Kawazoe, Y., Sugita, S., Keino, H., Yamada, Y., Imai, A., Horie, S., Mochizuki, M., 2012. Retinoic acid from retinal pigment epithelium induces T regulatory cells. Exp.Eye Res. 94, 32-40.

Kazama, H., Ricci, J.E., Herndon, J.M., Hoppe, G., Green, D.R., Ferguson, T.A., 2008. Induction of immunological tolerance by apoptotic cells requires caspase-dependent oxidation of high-mobility group box-1 protein. Immunity. 29, 21-32.

Kelly, B., O'Neill, L.A., 2015. Metabolic reprogramming in macrophages and dendritic cells in innate immunity. Cell Res. 25, 771-784.

Keren-Shaul, H., Spinrad, A., Weiner, A., Matcovitch-Natan, O., Dvir-Szternfeld, R., Ulland, T.K., David, E., Baruch, K., Lara-Astaiso, D., Toth, B., Itzkovitz, S., Colonna, M., Schwartz, M., Amit, I., 2017. A Unique Microglia Type Associated with Restricting Development of Alzheimer's Disease. Cell. 169, 1276-1290.e17. 
Krishnan, G., Chatterjee, N., 2012. Endocannabinoids alleviate proinflammatory conditions by modulating innate immune response in muller glia during inflammation. Glia. 60, 1629-1645.

Lehnardt, S., Henneke, P., Lien, E., Kasper, D.L., Volpe, J.J., Bechmann, I., Nitsch, R., Weber, J.R., Golenbock, D.T., Vartanian, T., 2006. A mechanism for neurodegeneration induced by group B streptococci through activation of the TLR2/MyD88 pathway in microglia. J.Immunol. 177, 583592.

Li, L., Eter, N., Heiduschka, P., 2015. The microglia in healthy and diseased retina. Exp.Eye Res.

Lin, J.B., Sene, A., Santeford, A., Fujiwara, H., Sidhu, R., Ligon, M.M., Shankar, V.A., Ban, N., Mysorekar, I.U., Ory, D.S., Apte, R.S., 2018. Oxysterol Signatures Distinguish Age-Related Macular Degeneration from Physiologic Aging. EBioMedicine. 32, 9-20.

Lopez, E.M., Tagliaferro, P., Onaivi, E.S., Lopez-Costa, J.J., 2011. Distribution of CB2 cannabinoid receptor in adult rat retina. Synapse. 65, 388-392.

Lopez-Luppo, M., Catita, J., Ramos, D., Navarro, M., Carretero, A., Mendes-Jorge, L., MunozCanoves, P., Rodriguez-Baeza, A., Nacher, V., Ruberte, J., 2017. Cellular Senescence Is Associated With Human Retinal Microaneurysm Formation During Aging. Invest.Ophthalmol.Vis.Sci. 58, 2832-2842.

Lucas, K., Karamichos, D., Mathew, R., Zieske, J.D., Stein-Streilein, J., 2012. Retinal laser burninduced neuropathy leads to substance P-dependent loss of ocular immune privilege. J.Immunol. $189,1237-1242$.

Ludwig, A., Mentlein, R., 2008. Glial cross-talk by transmembrane chemokines CX3CL1 and CXCL16. J.Neuroimmunol. 198, 92-97.

Lueck, K., Hennig, M., Lommatzsch, A., Pauleikhoff, D., Wasmuth, S., 2012. Complement and UV-irradiated photoreceptor outer segments increase the cytokine secretion by retinal pigment epithelial cells. Invest.Ophthalmol.Vis.Sci. 53, 1406-1413.

Luhmann, U.F., Robbie, S., Munro, P.M., Barker, S.E., Duran, Y., Luong, V., Fitzke, F.W., Bainbridge, J.W., Ali, R.R., MacLaren, R.E., 2009. The drusenlike phenotype in aging Ccl2knockout mice is caused by an accelerated accumulation of swollen autofluorescent subretinal macrophages. Invest.Ophthalmol.Vis.Sci. 50, 5934-5943.

Lui, H., Zhang, J., Makinson, S.R., Cahill, M.K., Kelley, K.W., Huang, H.Y., Shang, Y., Oldham, M.C., Martens, L.H., Gao, F., Coppola, G., Sloan, S.A., Hsieh, C.L., Kim, C.C., Bigio, E.H., Weintraub, S., Mesulam, M.M., Rademakers, R., Mackenzie, I.R., Seeley, W.W., Karydas, A., Miller, B.L., Borroni, B., Ghidoni, R., Farese, R.V.,Jr, Paz, J.T., Barres, B.A., Huang, E.J., 2016. Progranulin Deficiency Promotes Circuit-Specific Synaptic Pruning by Microglia via Complement Activation. Cell. 165, 921-935. 
Luo, C., Chen, M., Xu, H., 2011. Complement gene expression and regulation in mouse retina and retinal pigment epithelium/choroid. Mol.Vis. 17, 1588-1597.

Luo, C., Zhao, J., Chen, M., Xu, H., 2018. The expression of C1 inhibitor (C1INH) in macrophages is upregulated by retinal pigment epithelial cells - implication in subretinal immune privilege in the aging eye. Aging (Albany NY).

Luo, C., Zhao, J., Madden, A., Chen, M., Xu, H., 2013. Complement expression in retinal pigment epithelial cells is modulated by activated macrophages. Exp.Eye Res. 112C, 93-101.

Luu, J., Palczewski, K., 2018. Human aging and disease: Lessons from age-related macular degeneration. Proc.Natl.Acad.Sci.U.S.A. 115, 2866-2872.

Ma, W., Wong, W.T., 2016. Aging Changes in Retinal Microglia and their Relevance to Agerelated Retinal Disease. Adv.Exp.Med.Biol. 854, 73-78.

Mansour, H., Chamberlain, C.G., Weible, M.W.,2nd, Hughes, S., Chu, Y., Chan-Ling, T., 2008. Aging-related changes in astrocytes in the rat retina: imbalance between cell proliferation and cell death reduces astrocyte availability. Aging Cell. 7, 526-540.

Matias, I., Wang, J.W., Moriello, A.S., Nieves, A., Woodward, D.F., Di Marzo, V., 2006. Changes in endocannabinoid and palmitoylethanolamide levels in eye tissues of patients with diabetic retinopathy and age-related macular degeneration. Prostaglandins Leukot.Essent.Fatty Acids. 75, 413-418.

Mecca, C., Giambanco, I., Donato, R., Arcuri, C., 2018. Microglia and Aging: The Role of the TREM2-DAP12 and CX3CL1-CX3CR1 Axes. Int.J.Mol.Sci. 19, 10.3390/ijms19010318.

Mecha, M., Carrillo-Salinas, F.J., Feliu, A., Mestre, L., Guaza, C., 2016. Microglia activation states and cannabinoid system: Therapeutic implications. Pharmacol.Ther. 166, 40-55.

Medzhitov, R., Schneider, D.S., Soares, M.P., 2012. Disease tolerance as a defense strategy. Science. 335, 936-941.

Metea, M.R., Newman, E.A., 2007. Signalling within the neurovascular unit in the mammalian retina. Exp.Physiol. 92, 635-640.

Mevorach, D., Mascarenhas, J.O., Gershov, D., Elkon, K.B., 1998. Complement-dependent clearance of apoptotic cells by human macrophages. J.Exp.Med. 188, 2313-2320.

Mizuno, T., Kawanokuchi, J., Numata, K., Suzumura, A., 2003. Production and neuroprotective functions of fractalkine in the central nervous system. Brain Res. 979, 65-70.

Mochizuki, M., Kuwabara, T., McAllister, C., Nussenblatt, R.B., Gery, I., 1985. Adoptive transfer of experimental autoimmune uveoretinitis in rats. Immunopathogenic mechanisms and histologic features. Invest.Ophthalmol.Vis.Sci. 26, 1-9. 
Mochizuki, M., Sugita, S., Kamoi, K., 2013. Immunological homeostasis of the eye. Prog.Retin.Eye Res. 33, 10-27.

Morrison, J.H., Baxter, M.G., 2012. The ageing cortical synapse: hallmarks and implications for cognitive decline. Nat.Rev.Neurosci. 13, 240-250.

Muoio, V., Persson, P.B., Sendeski, M.M., 2014. The neurovascular unit - concept review. Acta Physiol.(Oxf). 210, 790-798.

Nag, T.C., Wadhwa, S., Alladi, P.A., Sanyal, T., 2011. Localization of 4-hydroxy 2-nonenal immunoreactivity in aging human retinal Muller cells. Ann.Anat. 193, 205-210.

Nimmerjahn, A., Kirchhoff, F., Helmchen, F., 2005. Resting microglial cells are highly dynamic surveillants of brain parenchyma in vivo. Science. 308, 1314-1318.

Orihuela, R., McPherson, C.A., Harry, G.J., 2016. Microglial M1/M2 polarization and metabolic states. Br.J.Pharmacol. 173, 649-665.

Paglinawan, R., Malipiero, U., Schlapbach, R., Frei, K., Reith, W., Fontana, A., 2003. TGFbeta directs gene expression of activated microglia to an anti-inflammatory phenotype strongly focusing on chemokine genes and cell migratory genes. Glia. 44, 219-231.

Painter, M.M., Atagi, Y., Liu, C.C., Rademakers, R., Xu, H., Fryer, J.D., Bu, G., 2015. TREM2 in CNS homeostasis and neurodegenerative disease. Mol.Neurodegener. 10, 43-015-0040-9.

Pascual, A.C., Gaveglio, V.L., Giusto, N.M., Pasquare, S.J., 2014. Cannabinoid receptor-dependent metabolism of 2-arachidonoylglycerol during aging. Exp.Gerontol. 55, 134-142.

Pascual, A.C., Gaveglio, V.L., Giusto, N.M., Pasquare, S.J., 2013. Aging modifies the enzymatic activities involved in 2-arachidonoylglycerol metabolism. Biofactors. 39, 209-220.

Pascual, A.C., Martin-Moreno, A.M., Giusto, N.M., de Ceballos, M.L., Pasquare, S.J., 2014. Normal aging in rats and pathological aging in human Alzheimer's disease decrease FAAH activity: modulation by cannabinoid agonists. Exp.Gerontol. 60, 92-99.

Pearce, E.L., Poffenberger, M.C., Chang, C.H., Jones, R.G., 2013. Fueling immunity: insights into metabolism and lymphocyte function. Science. 342, 1242454.

Pettersen, R.D., 2000. CD47 and death signaling in the immune system. Apoptosis. 5, 299-306.

Piccio, L., Buonsanti, C., Mariani, M., Cella, M., Gilfillan, S., Cross, A.H., Colonna, M., PaninaBordignon, P., 2007. Blockade of TREM-2 exacerbates experimental autoimmune encephalomyelitis. Eur.J.Immunol. 37, 1290-1301. 
Poliani, P.L., Wang, Y., Fontana, E., Robinette, M.L., Yamanishi, Y., Gilfillan, S., Colonna, M., 2015. TREM2 sustains microglial expansion during aging and response to demyelination.

J.Clin.Invest. 125, 2161-2170.

Provis, J.M., Penfold, P.L., Edwards, A.J., van Driel, D., 1995. Human retinal microglia: expression of immune markers and relationship to the glia limitans. Glia. 14, 243-256.

Qiao, H., Lucas, K., Stein-Streilein, J., 2009. Retinal laser burn disrupts immune privilege in the eye. Am.J.Pathol. 174, 414-422.

Rajapakse, D., Chen, M., Curtis, T.M., Xu, H., 2017. PKCzeta-dependent upregulation of p27kip1 contributes to oxidative stress induced retinal pigment epithelial cell multinucleation. Aging (Albany NY). 9, 2052-2068.

Raoul, W., Feumi, C., Keller, N., Lavalette, S., Houssier, M., Behar-Cohen, F., Combadiere, C., Sennlaub, F., 2008. Lipid-bloated subretinal microglial cells are at the origin of drusen appearance in CX3CR1-deficient mice. Ophthalmic Res. 40, 115-119.

Raoul, W., Keller, N., Rodero, M., Behar-Cohen, F., Sennlaub, F., Combadiere, C., 2008. Role of the chemokine receptor CX3CR1 in the mobilization of phagocytic retinal microglial cells. J.Neuroimmunol. 198, 56-61.

Remmerie, A., Scott, C.L., 2018. Macrophages and lipid metabolism. Cell.Immunol. 330, 27-42.

Rosenbaum, J.T., McDevitt, H.O., Guss, R.B., Egbert, P.R., 1980. Endotoxin-induced uveitis in rats as a model for human disease. Nature. 286, 611-613.

Safaiyan, S., Kannaiyan, N., Snaidero, N., Brioschi, S., Biber, K., Yona, S., Edinger, A.L., Jung, S., Rossner, M.J., Simons, M., 2016. Age-related myelin degradation burdens the clearance function of microglia during aging. Nat.Neurosci. 19, 995-998.

Sarfati, M., Fortin, G., Raymond, M., Susin, S., 2008. CD47 in the immune response: role of thrombospondin and SIRP-alpha reverse signaling. Curr.Drug Targets. 9, 842-850.

Schwitzer, T., Schwan, R., Angioi-Duprez, K., Giersch, A., Laprevote, V., 2016. The

Endocannabinoid System in the Retina: From Physiology to Practical and Therapeutic Applications. Neural Plast. 2016, 2916732.

Sennlaub, F., Auvynet, C., Calippe, B., Lavalette, S., Poupel, L., Hu, S.J., Dominguez, E., Camelo, S., Levy, O., Guyon, E., Saederup, N., Charo, I.F., Rooijen, N.V., Nandrot, E., Bourges, J.L., Behar-Cohen, F., Sahel, J.A., Guillonneau, X., Raoul, W., Combadiere, C., 2013. CCR2(+) monocytes infiltrate atrophic lesions in age-related macular disease and mediate photoreceptor degeneration in experimental subretinal inflammation in Cx3cr1 deficient mice. EMBO Mol.Med. $5,1775-1793$. 
Singh, A., Falk, M.K., Hviid, T.V., Sorensen, T.L., 2013. Increased expression of CD200 on circulating CD11b+ monocytes in patients with neovascular age-related macular degeneration. Ophthalmology. 120, 1029-1037.

Stefansson, E., Geirsdottir, A., Sigurdsson, H., 2011. Metabolic physiology in age related macular degeneration. Prog.Retin.Eye Res. 30, 72-80.

Straiker, A., Stella, N., Piomelli, D., Mackie, K., Karten, H.J., Maguire, G., 1999. Cannabinoid CB1 receptors and ligands in vertebrate retina: localization and function of an endogenous signaling system. Proc.Natl.Acad.Sci.U.S.A. 96, 14565-14570.

Streilein, J.W., 1999. Immunoregulatory mechanisms of the eye. Prog.Retin.Eye Res. 18, 357-370.

Streilein, J.W., 1995. Immunological non-responsiveness and acquisition of tolerance in relation to immune privilege in the eye. Eye. 9 ( $\mathrm{Pt}$ 2), 236-240.

Streilein, J.W., Ma, N., Wenkel, H., Ng, T.F., Zamiri, P., 2002. Immunobiology and privilege of neuronal retina and pigment epithelium transplants. Vision Res. 42, 487-495.

Sugita, S., Horie, S., Nakamura, O., Futagami, Y., Takase, H., Keino, H., Aburatani, H., Katunuma, N., Ishidoh, K., Yamamoto, Y., Mochizuki, M., 2008. Retinal pigment epithelium-derived CTLA2alpha induces TGFbeta-producing T regulatory cells. J.Immunol. 181, 7525-7536.

Sugita, S., Usui, Y., Horie, S., Futagami, Y., Aburatani, H., Okazaki, T., Honjo, T., Takeuchi, M., Mochizuki, M., 2009. T cell suppression by programmed cell death 1 ligand 1 on retinal pigment epithelium during inflammatory conditions. Invest.Ophthalmol.Vis.Sci.

Takizawa, F., Tsuji, S., Nagasawa, S., 1996. Enhancement of macrophage phagocytosis upon iC3b deposition on apoptotic cells. FEBS Lett. 397, 269-272.

Tezel, G., Edward, D.P., Wax, M.B., 1999. Serum autoantibodies to optic nerve head glycosaminoglycans in patients with glaucoma. Arch.Ophthalmol. 117, 917-924.

Tezel, G., Yang, J., Wax, M.B., 2004. Heat shock proteins, immunity and glaucoma. Brain Res.Bull. 62, 473-480.

Turnbull, I.R., Gilfillan, S., Cella, M., Aoshi, T., Miller, M., Piccio, L., Hernandez, M., Colonna, M., 2006. Cutting edge: TREM-2 attenuates macrophage activation. J.Immunol. 177, 3520-3524.

Vagaja, N.N., Chinnery, H.R., Binz, N., Kezic, J.M., Rakoczy, E.P., McMenamin, P.G., 2012. Changes in murine hyalocytes are valuable early indicators of ocular disease.

Invest.Ophthalmol.Vis.Sci. 53, 1445-1451.

Wang, A.L., Lukas, T.J., Yuan, M., Du, N., Tso, M.O., Neufeld, A.H., 2009. Autophagy and exosomes in the aged retinal pigment epithelium: possible relevance to drusen formation and agerelated macular degeneration. PLoS One. 4, e4160. 
Wang, Y., Grenell, A., Zhong, F., Yam, M., Hauer, A., Gregor, E., Zhu, S., Lohner, D., Zhu, J., Du, J., 2018. Metabolic signature of the aging eye in mice. Neurobiol.Aging. 71, 223-233.

Wax, M.B., Tezel, G., Kawase, K., Kitazawa, Y., 2001. Serum autoantibodies to heat shock proteins in glaucoma patients from Japan and the United States. Ophthalmology. 108, 296-302.

Wax, M.B., Yang, J., Tezel, G., 2001. Serum autoantibodies in patients with glaucoma. J.Glaucoma. 10, S22-4.

Wei, Y., Wang, X., Wang, L., 2009. Presence and regulation of cannabinoid receptors in human retinal pigment epithelial cells. Mol.Vis. 15, 1243-1251.

Welge-Lussen, U., Wilsch, C., Neuhardt, T., Wayne Streilein, J., Lutjen-Drecoll, E., 1999. Loss of anterior chamber-associated immune deviation (ACAID) in aged retinal degeneration (rd) mice. Invest.Ophthalmol.Vis.Sci. 40, 3209-3214.

Wen, X., Hu, X., Miao, L., Ge, X., Deng, Y., Bible, P.W., Wei, L., 2018. Epigenetics, microbiota, and intraocular inflammation: New paradigms of immune regulation in the eye. Prog.Retin.Eye Res. 64, 84-95.

Wenkel, H., Chen, P.W., Ksander, B.R., Streilein, J.W., 1999. Immune privilege is extended, then withdrawn, from allogeneic tumor cell grafts placed in the subretinal space.

Invest.Ophthalmol.Vis.Sci. 40, 3202-3208.

Wright, G.J., Jones, M., Puklavec, M.J., Brown, M.H., Barclay, A.N., 2001. The unusual distribution of the neuronal/lymphoid cell surface CD200 (OX2) glycoprotein is conserved in humans. Immunology. 102, 173-179.

Wright, G.J., Puklavec, M.J., Willis, A.C., Hoek, R.M., Sedgwick, J.D., Brown, M.H., Barclay, A.N., 2000. Lymphoid/neuronal cell surface OX2 glycoprotein recognizes a novel receptor on macrophages implicated in the control of their function. Immunity. 13, 233-242.

Xie, X., Luo, X., Liu, N., Li, X., Lou, F., Zheng, Y., Ren, Y., 2017. Monocytes, microglia, and CD200-CD200R1 signaling are essential in the transmission of inflammation from the periphery to the central nervous system. J.Neurochem. 141, 222-235.

$\mathrm{Xu}, \mathrm{H}$., Chen, M., 2016. Targeting the complement system for the management of retinal inflammatory and degenerative diseases. Eur.J.Pharmacol.

Xu, H., Chen, M., Forrester, J.V., 2009. Para-inflammation in the aging retina. Prog.Retin.Eye Res. 28, 348-368.

Xu, H., Chen, M., Manivannan, A., Lois, N., Forrester, J.V., 2008. Age-dependent accumulation of lipofuscin in perivascular and subretinal microglia in experimental mice. Aging Cell. 7, 58-68. 
Xu, H., Cheng, C.L., Chen, M., Manivannan, A., Cabay, L., Pertwee, R.G., Coutts, A., Forrester, J.V., 2007. Anti-inflammatory property of the cannabinoid receptor-2-selective agonist JWH-133 in a rodent model of autoimmune uveoretinitis. J.Leukoc.Biol. 82, 532-541.

Xu, H., Dawson, R., Forrester, J.V., Liversidge, J., 2007. Identification of novel dendritic cell populations in normal mouse retina. Invest.Ophthalmol.Vis.Sci. 48, 1701-1710.

Yazulla, S., 2008. Endocannabinoids in the retina: from marijuana to neuroprotection. Prog.Retin.Eye Res. 27, 501-526.

Yeh, F.L., Hansen, D.V., Sheng, M., 2017. TREM2, Microglia, and Neurodegenerative Diseases. Trends Mol.Med. 23, 512-533.

Yu, D.Y., Cringle, S.J., 2001. Oxygen distribution and consumption within the retina in vascularised and avascular retinas and in animal models of retinal disease. Prog.Retin.Eye Res. 20, 175-208.

Zamiri, P., Masli, S., Kitaichi, N., Taylor, A.W., Streilein, J.W., 2005. Thrombospondin plays a vital role in the immune privilege of the eye. Invest.Ophthalmol.Vis.Sci. 46, 908-919.

Zamiri, P., Masli, S., Streilein, J.W., Taylor, A.W., 2006. Pigment epithelial growth factor suppresses inflammation by modulating macrophage activation. Invest.Ophthalmol.Vis.Sci. 47, 3912-3918.

Zamiri, P., Sugita, S., Streilein, J.W., 2007. Immunosuppressive properties of the pigmented epithelial cells and the subretinal space. Chem.Immunol.Allergy. 92, 86-93.

Zhang, H., Li, F., Yang, Y., Chen, J., Hu, X., 2015. SIRP/CD47 signaling in neurological disorders. Brain Res. 1623, 74-80.

Zhao, L., Zabel, M.K., Wang, X., Ma, W., Shah, P., Fariss, R.N., Qian, H., Parkhurst, C.N., Gan, W.B., Wong, W.T., 2015. Microglial phagocytosis of living photoreceptors contributes to inherited retinal degeneration. EMBO Mol.Med. 7, 1179-1197.

Zujovic, V., Benavides, J., Vige, X., Carter, C., Taupin, V., 2000. Fractalkine modulates TNF-alpha secretion and neurotoxicity induced by microglial activation. Glia. 29, 305-315. 


\section{Figure legends}

Figure 1. Immune cells in the aged retina. Retinal flatmounts from 24 months old C57BL/6J mice were stained for Iba-1 (green), Isolectin B4 (blue), and CD3 (red in A) or B200 (red in B) and imaged by confocal microscopy. Arrows indicating intravascular leukocytes.

Figure 2. Tight-junctions and subretinal immune cells in retinal pigment epithelial cells of the aged eye. (A) RPE-choroidal flatmounts from 24 months old C57BL/6J mice were stained for claudin-1 (Green), ZO-1 (red), and Phalloidin (blue) and imaged by confocal microscopy. Arrows indicate area of ZO-1 loss with no defect in claudin-1 and F-actin (by phalloidin labelling) expression. (B, C) RPE-choroidal flatmounts from 24 months old C57BL/6J mice were stained for Iba-1 (Green) and CD3 (red in B) or isolectin B4 (red in C) and imaged by confocal microscopy. Arrowheads: cells dual-positive for Iba-1 and isolectin B4.

Figure 3. The expression of CD200-CD200R and CD47-SIRP in mouse retina. (A, B) Confocal images showing CD200 (A) and CD200R (B) expression in the retina from 3 months old C57BL/6J mice. (C, D) mRNA expression levels of CD200 (C) and CD200R (D) in the retina from 3 months (young) and 24 months (old) C57BL/6J mice. (E, F) Confocal images showing CD47 (E) and SIRP (F) expression in the retina from 3 months old C57BL/6J mice. $(\mathrm{G}, \mathrm{H})$ mRNA expression levels of CD47 (G) and SIRP (H) in the retina from 3 months (young) and 24 months (old) C57BL/6J mice. Mean \pm SEM, $\mathrm{n}=5$.

Figure 4. Age-related changes in endocannabinoids 2-AG and AEA in mouse retina. Retinal tissues from 3, 18 and 27 months old C57BL/6J and CCL2 ${ }^{-/-}$mice were snap-frozen and processed for measuring of 2-AG and AEA using liquid chromatography/mass spectrometry. The values of 2AG and AEA were normalized by tissue weights and total protein content. (A) 2-AG levels in the retina of WT mice at different ages. (B) AEA levels in the retina of WT mice at different ages. (C, D) Comparison of retinal 2-AG (C) and AEA (D) levels between WT and CCL2 ${ }^{-/}$mice at different ages. $\mathrm{N} \geq 6$ mice. ${ }^{*}, \mathrm{P}<0.05$.

Figure 5. The effect of RPE on macrophage gene expression. (A, B) Bone marrow-derived macrophages (BMDMs) and primary RPE cells were cultured from 3 months old C57BL/6J mice. RPE cells were then treated with oxidized photoreceptor outer segments (oxPOS) for $24 \mathrm{~h}$. BMDMs 
were co-cultured with RPE cells for $7 \mathrm{~h}$. Cells were detached in ice-cold PBS with 2mM EDTA. Macrophages were then isolated by CD11b MACS kit (Miltenyi Biotec, UK) and processed for realtime RT-PCR. (A) Genes related to the inflammatory M1 phenotype. (B) Genes related to the M2 phenotype. Data shown are gene fold changes compared with macrophages without RPE treatment. RPE(-) - BMDMs alone; RPE(+) - BMDMs co-cultured with normal RPE cells; oxPOSRPE(+) BMDMs co-cultured with oxPOS-treated RPE cells. Mean \pm SEM, $\mathrm{n}=3$. *, $\mathrm{P}<0.05 ; * *, \mathrm{P}<0.01$ compared with macrophages without RPE treatment. ${ }^{\dagger}, \mathrm{P}<0.05$ compared with normal RPE treated macrophages.

Figure 6. The effect of RPE cells on macrophage phagocytosis. $\mathrm{CD} 4^{+} \mathrm{T}$ cells were isolated from 3 months old C57BL/6J mice and were labeled with MitoTracker Orange. Apoptosis was induced by serum deprivation. Primary RPE cells were treated with oxPOS for $24 \mathrm{~h}$. Bone marrow-derived macrophages, either untreated, or pre-treated with normal RPE, or oxPOS-treated RPE, were labeled with Calcein AM. Macrophages were then supplemented with apoptotic T cells (macrophage: T cell ratio $=1: 10$ ) for $24 \mathrm{~h}$. Remaining $\mathrm{T}$ cells were counted at the end of the study. (A) Apoptotic T cells without macrophages. (B) Apoptotic $\mathrm{T}$ cells incubated with normal macrophages for $24 \mathrm{~h}$. (C) Apoptotic T cells incubated with normal RPE pre-treated macrophages. (D) Apoptotic T cells incubated with macrophages that were pre-treated with oxPOS-treated RPE cells. apoCD4 - apoptotic CD4 T cells; Mac - macrophages; Mac(RPE) - macrophages pre-treated with normal RPE cells; Mac(oxRPE) - macrophages pre-treated with oxPOS-treated RPE cells. Mean \pm SEM, n = 3. *, $\mathrm{P}<0.05$. Scale bar $=50 \mu \mathrm{m}$.

Figure 7. Age-related alterations in retinal microglial activation and function. (A) Under normal physiological conditions, microglia patrol retinal microenvironment through crawling dendrites. Microglia may be activated after engaging with Damage Associated Molecular Patterns (DAMPs) by cell surface receptors such as TLRs, NLRs and IL-1Rs. This activation process is tightly controlled by various signals from surrounding neurons (e.g., CX3CL1-CX3CR1, CD200-CD200R, CD47SIRP-1, etc.). (B) During aging, oxidative stress damages retinal neurons leading to the weakening of negative regulatory signals and the accumulation of DAMPs. This results in low-levels of sustained microglial activation. In the meantime, sustained chronic oxidative stress also damages microglial function. 
Figure 8. Age-related changes in retinal complement expression. (A) Under normal physiological conditions, retinal cells, including microglia, RPE and neurons express various complements and complement regulators. The expression levels of complement inhibitors such as CFH, C1INH and CD59 is relatively higher than that of complement components such as C3 and C5. Low levels of complement expression and activation is critical for retinal homeostasis. (B) During aging, oxidative stress and low-levels of inflammation reduce the expression of complement inhibitors but increase the expression of complement components (e.g., CFB and C3). BM - Bruch's Membrane; RPE retinal pigment epithelium; $\mathrm{CFB}$ - complement factor $\mathrm{B}$; $\mathrm{CFH}$ - complement factor $\mathrm{H}, \mathrm{C} 1 \mathrm{INH}-\mathrm{C} 1$ inhibitor; $\mathrm{C} 4 \mathrm{BP}$ - $\mathrm{C} 4$ binding protein; $\mathrm{M} \phi$ - macrophage 
Table 1. Retinal defense mechanisms in normal aging and age-related disease conditions

\begin{tabular}{|c|c|c|c|c|}
\hline $\begin{array}{c}\text { Defense } \\
\text { strategies }\end{array}$ & & Young Retina & Aging Retina & Degenerative Retina \\
\hline Avoidance & & $\begin{array}{l}\text { Intact iBRB and } \\
\text { oBRB }\end{array}$ & $\begin{array}{l}\diamond \text { Discrete breach of } \mathrm{iBRB} \\
\text { and oBRB, may be } \\
\text { repaired (transient). }\end{array}$ & $\begin{array}{l}\diamond \text { Substantial damage of } \\
\text { iBRB and oBRB at the } \\
\text { lesion site, unable to } \\
\text { repair. }\end{array}$ \\
\hline Tolerance & $\diamond$ & $\begin{array}{l}\text { Strong } \\
\text { suppressive and } \\
\text { tolerogenic } \\
\text { signals from } \\
\text { neurons and RPE } \\
\text { cells. } \\
\text { Ocular } \\
\text { compartment- } \\
\text { mediated immune } \\
\text { deviation } \\
\text { maintained } \\
\text { (ACAID, VAID, } \\
\text { SRSID). }\end{array}$ & $\begin{array}{llr}\diamond & \text { Reduced: } & \text { CD200, } \\
& \text { CX3CR1, TGF } \beta, \\
& \text { TREM2, others (?). } \\
\diamond & \text { Increased: IL-10, } \\
& \text { endocannabinoids, } \\
& \text { others (?) } \\
\diamond & \text { Ocular compartment- } \\
& \begin{array}{l}\text { mediated immune } \\
\text { deviation maintained. }\end{array}\end{array}$ & $\begin{array}{l}\diamond \text { Reduced or complete loss } \\
\text { of inhibitory signals from } \\
\text { neurons and RPE cells at } \\
\text { the lesion site. The } \\
\text { remaining neurons and } \\
\text { RPE cells may maintain } \\
\text { immune suppressive with } \\
\text { reduced capacity. } \\
\diamond \text { Loss of ocular } \\
\text { compartment-mediated } \\
\text { immune deviation. }\end{array}$ \\
\hline $\begin{array}{r}\text { Outcome } \\
\text { on } \\
\text { Immune } \\
\text { privilege }\end{array}$ & $\diamond$ & $\begin{array}{l}\text { Retina maintains } \\
\text { as an immune } \\
\text { privileged tissue; } \\
\text { Vitreous cavity } \\
\text { and subretinal } \\
\text { space are immune } \\
\text { privileged sites. }\end{array}$ & $\begin{array}{l}\diamond \text { Retina remains } \\
\text { privileged, but at risk of } \\
\text { immune attach due to } \\
\text { weak barriers and } \\
\text { reduced suppressive } \\
\text { capacity. } \\
\diamond \text { Vitreous cavity and } \\
\text { subretinal space remain } \\
\text { as sites of IP, but at risk } \\
\text { of inducing } \\
\text { inflammation due to } \\
\text { low-level of immune } \\
\text { cell infiltration. }\end{array}$ & $\begin{array}{l}\diamond \text { Retina suffers from } \\
\text { inflammatory attack at the } \\
\text { lesion site. The unaffected } \\
\text { area may remain partially } \\
\text { privileged. } \\
\diamond \text { Vitreous cavity (e.g., in } \\
\text { DR) and subretinal space } \\
\text { (e.g., in AMD) may lose } \\
\text { immune regulatory } \\
\text { capacity. }\end{array}$ \\
\hline Defense & & $\begin{array}{l}\text { Resting microglia } \\
\text { patrolling } \\
\text { microenvironment } \\
\text { using motile } \\
\text { dendrites. } \\
\text { Low-levels of } \\
\text { complement } \\
\text { expression } \\
\text { without overt } \\
\text { complement }\end{array}$ & $\begin{array}{rlr}\diamond & \text { Microglia undergo mild } \\
& \text { activation and low- } \\
& \text { levels of proliferation. } \\
\diamond & \text { Microglia migrate to out } \\
& \text { retinal layers and } \\
& \text { subretinal space. } \\
\diamond & \text { Low levels of } \\
& \text { macrophage infiltration } \\
& (?) \\
\diamond & \text { Low levels of }\end{array}$ & $\begin{array}{ll}\diamond & \text { Microglia activation. } \\
\diamond & \text { Immune cell ( } \mathrm{T} \text { cells, } \\
& \text { macrophages, } \\
& \text { neutrophils, } \\
& \text { infiltration. } \\
\diamond & \text { Dysregulated } \\
& \text { complement activation. }\end{array}$ \\
\hline
\end{tabular}




\begin{tabular}{|l|l|l|l|}
\hline activation. & $\begin{array}{r}\text { complement activation } \\
\text { in neuronal retina and } \\
\text { retina-choroid interface. }\end{array}$ & \\
\hline Outcomes & Maintain homeostasis & $\begin{array}{l}\text { Re-adjust homeostatic set } \\
\text { point, vulnerable to further } \\
\text { internal and external insults. }\end{array}$ & $\begin{array}{l}\text { Tissue damage and } \\
\text { destruction, loss of function. }\end{array}$ \\
\hline
\end{tabular}


Figure 1
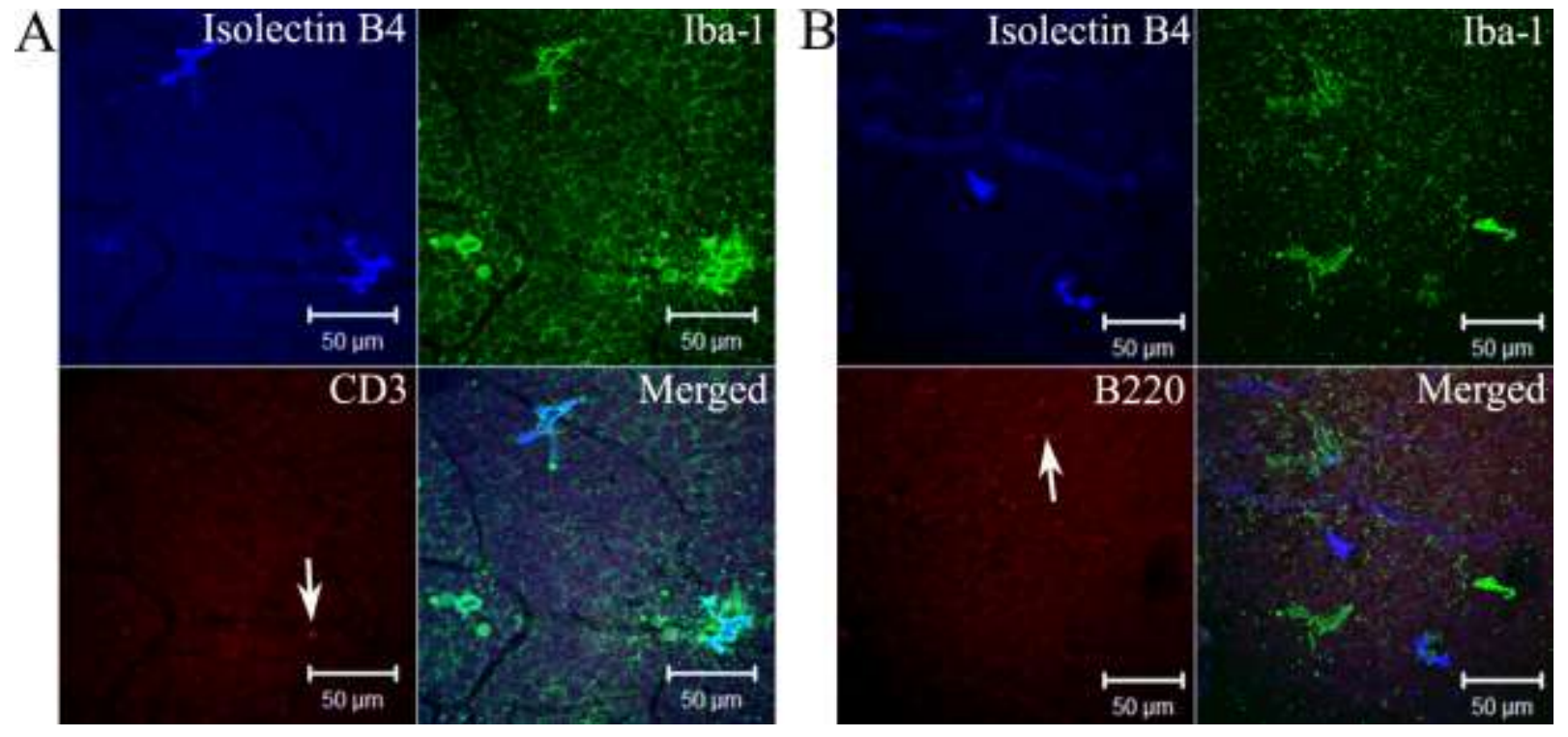

Figure 2
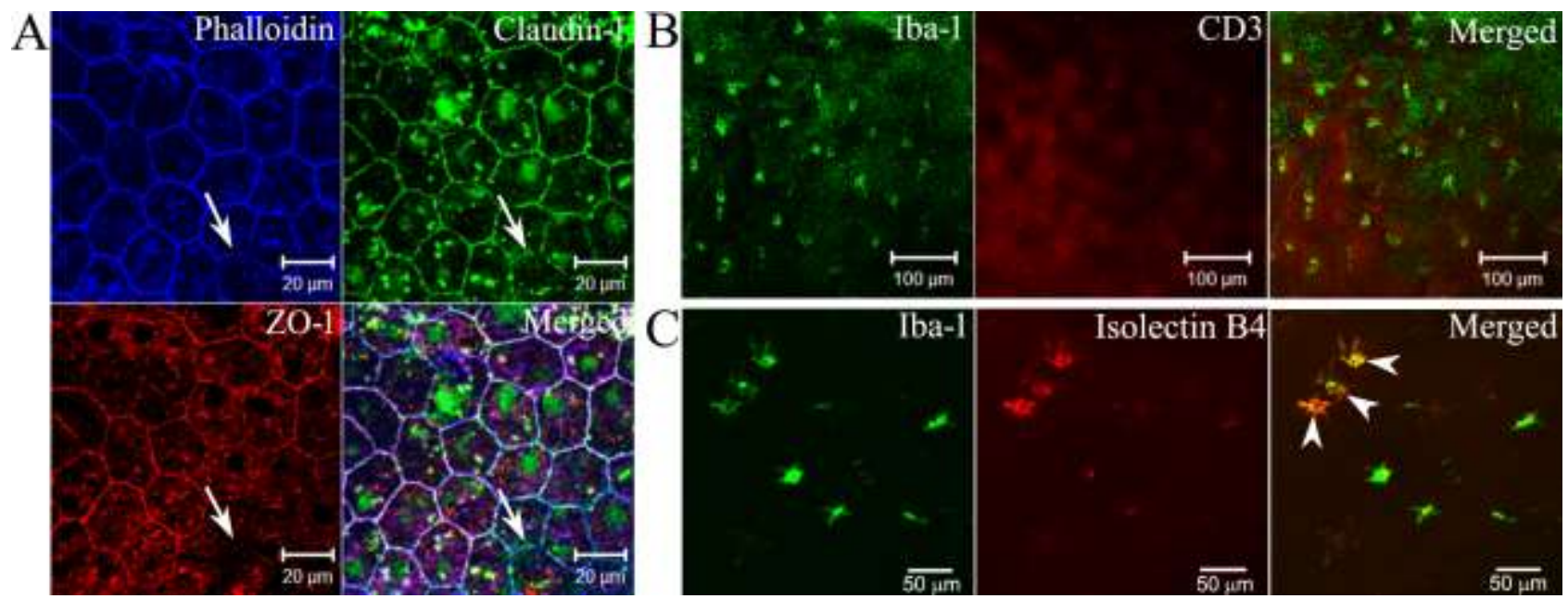
Figure 3
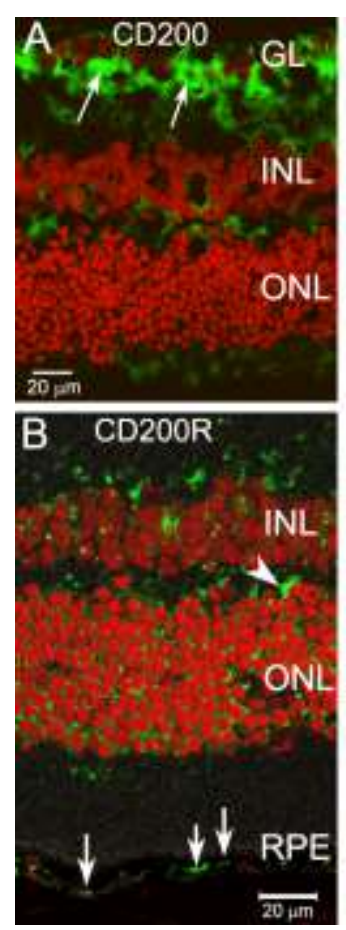
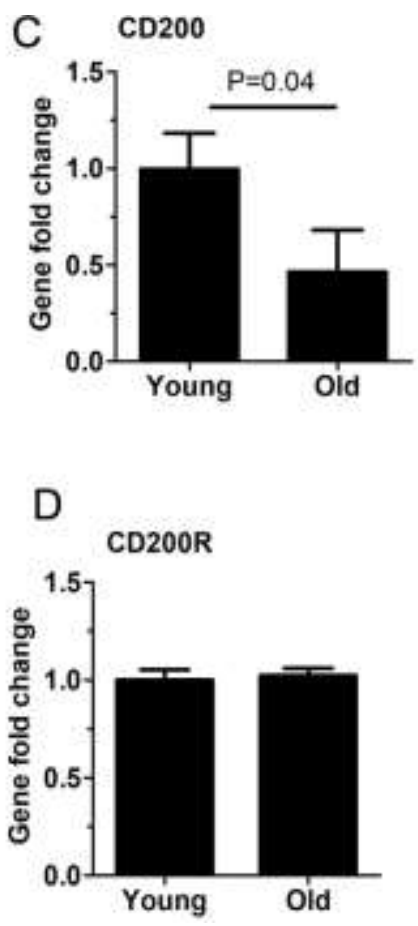
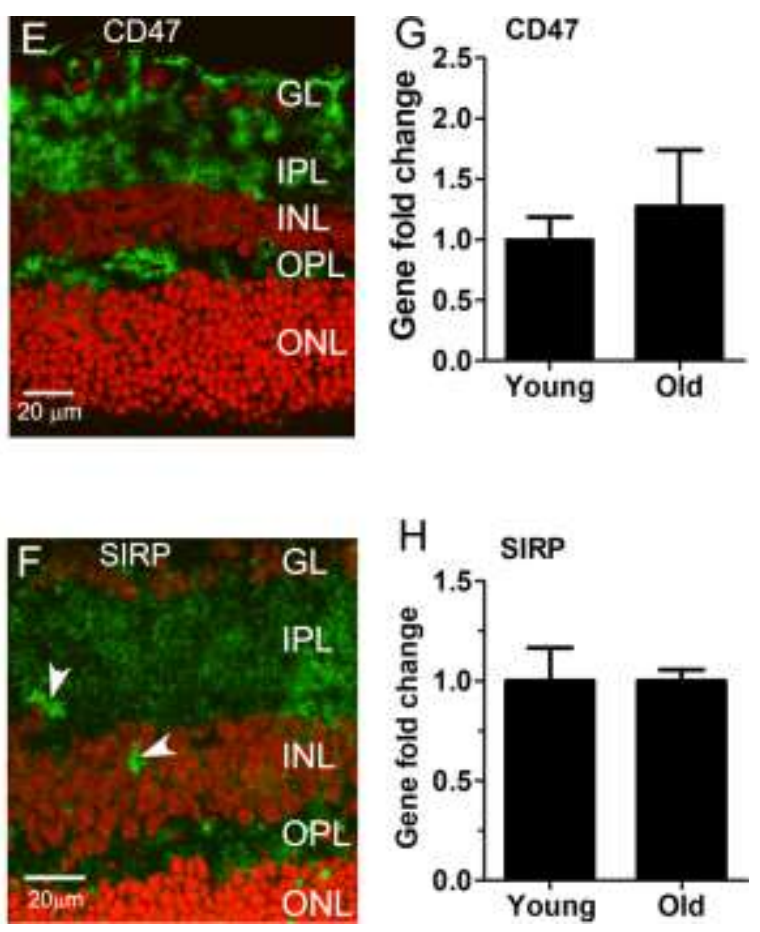

Figure 4
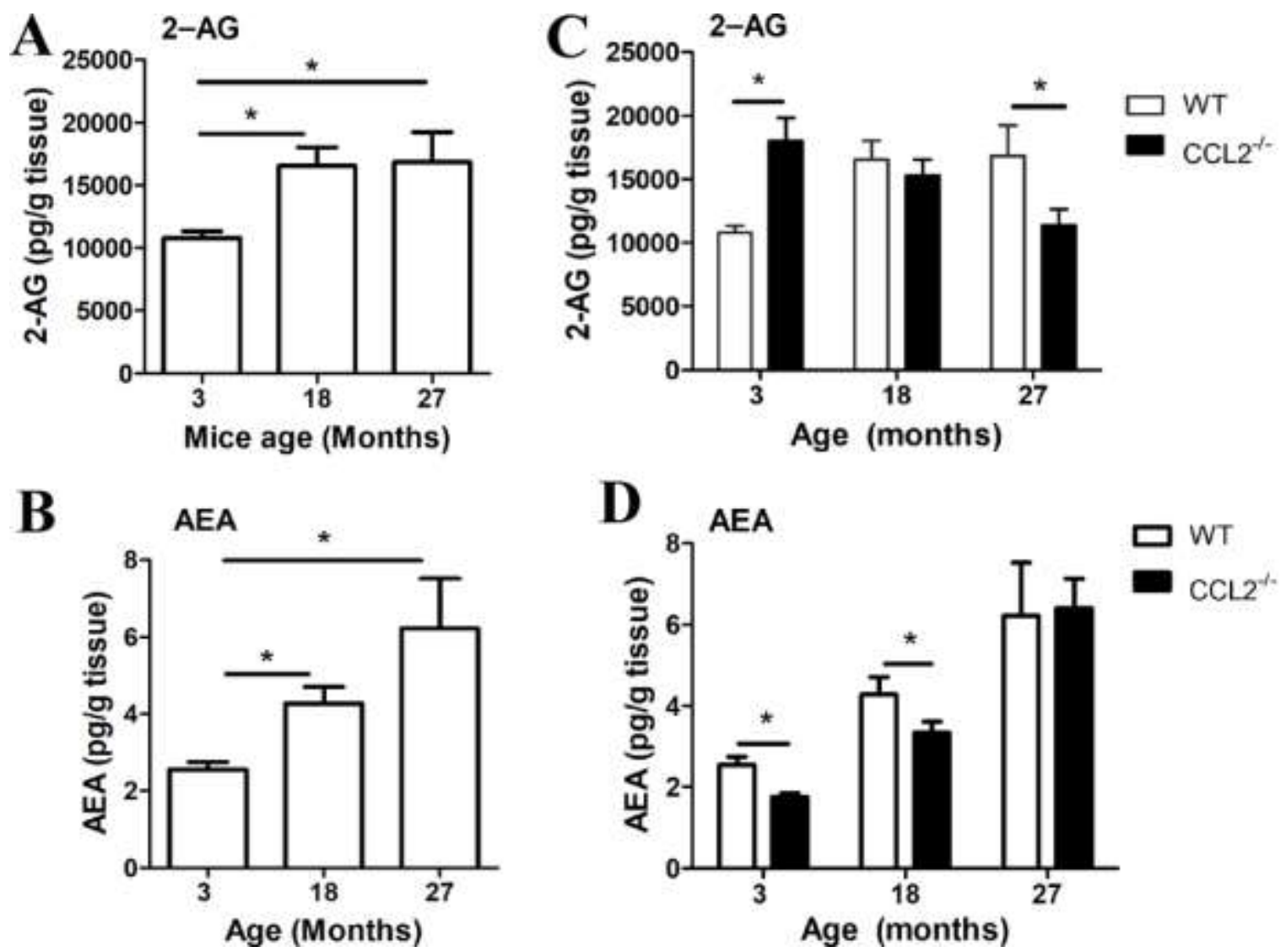
Figure 5
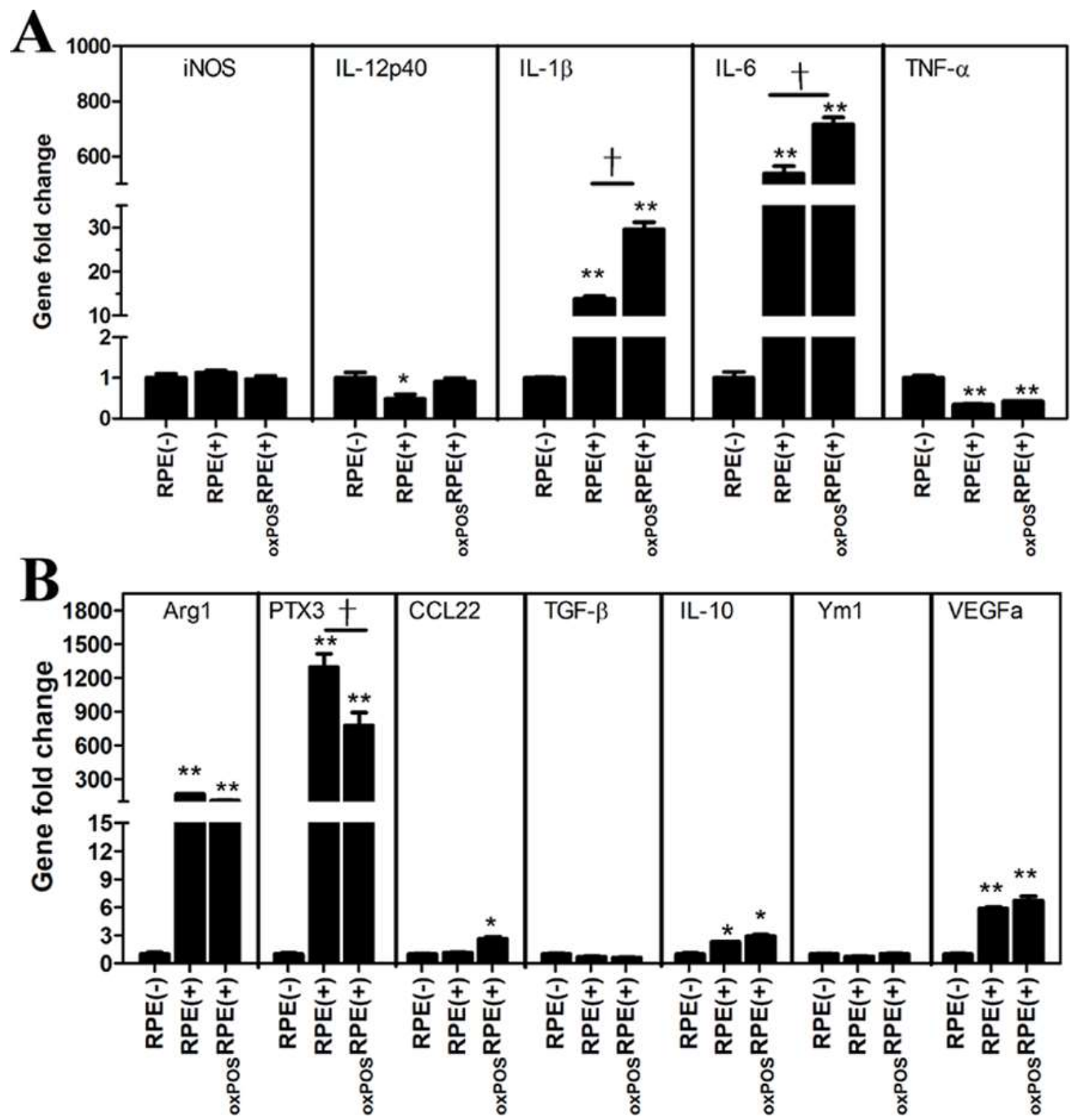
Figure 6
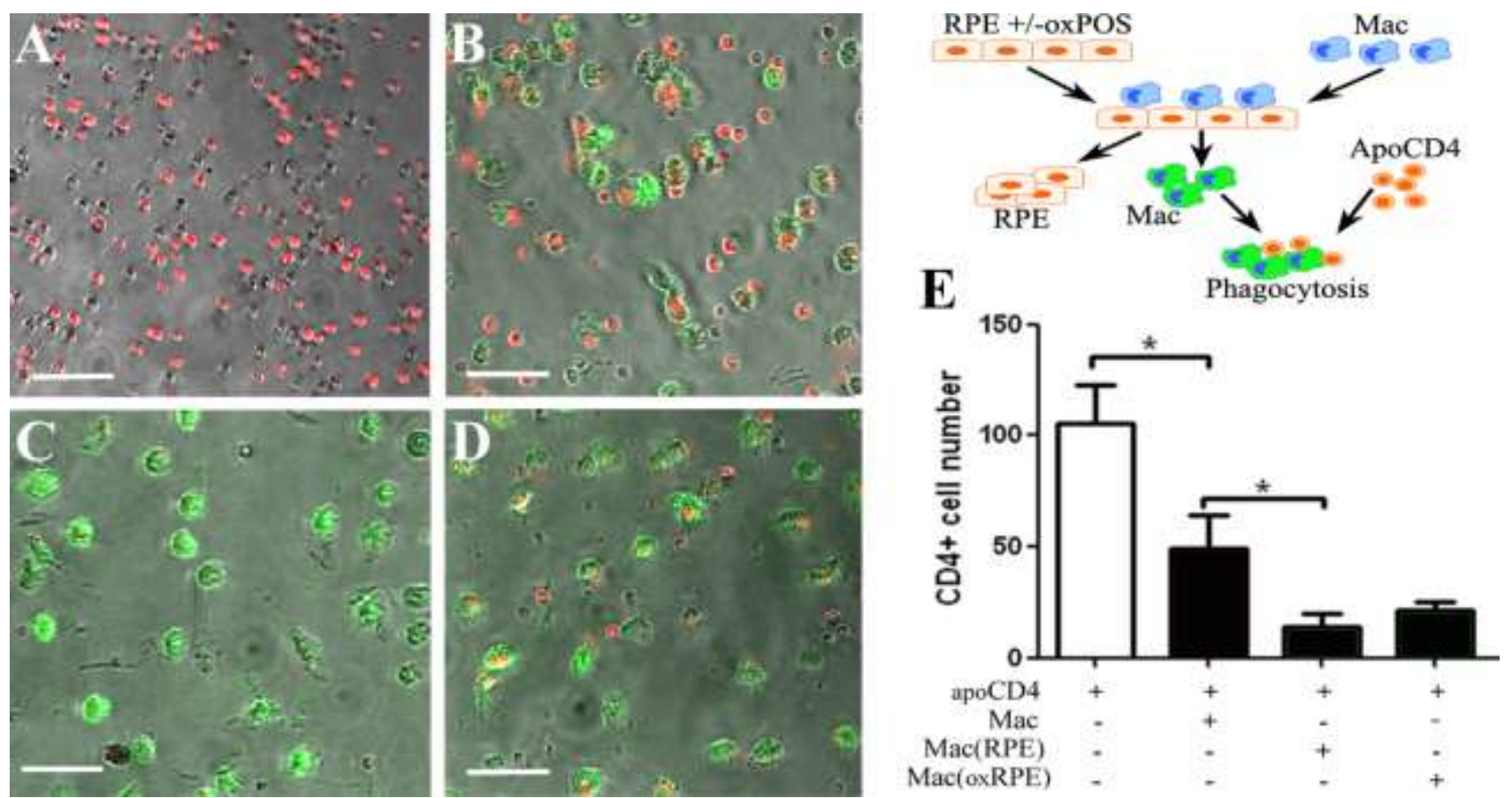

Figure 7

A

Young

Activation
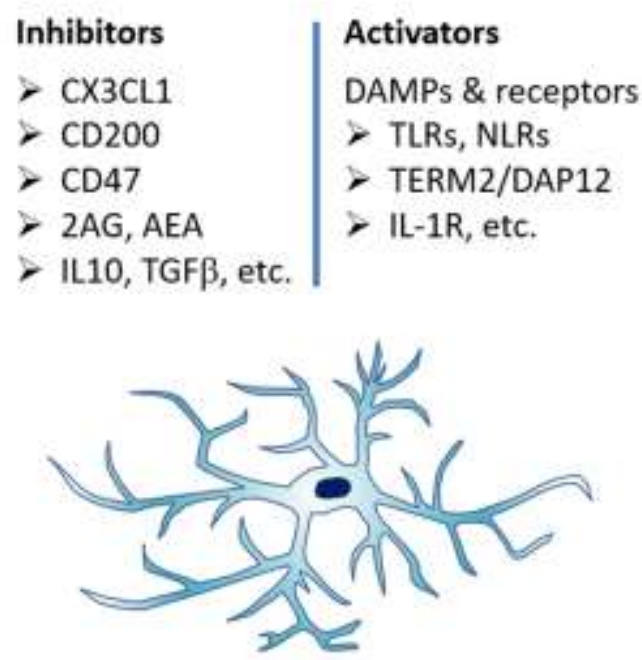

\section{Function:}

Patrolling (migration), phagocytizing debris, synaptic pruning.
B

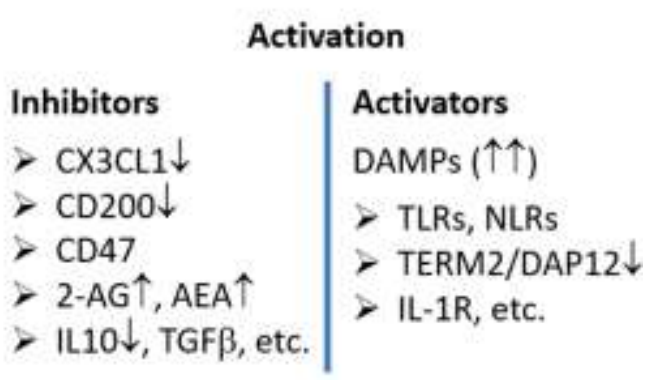

\section{Function:}

Migration $\downarrow$, phagocytosis $\downarrow$, basal levels of cytokine release $\uparrow$, immune response $\downarrow$ 
Figure 8

\section{A Young}

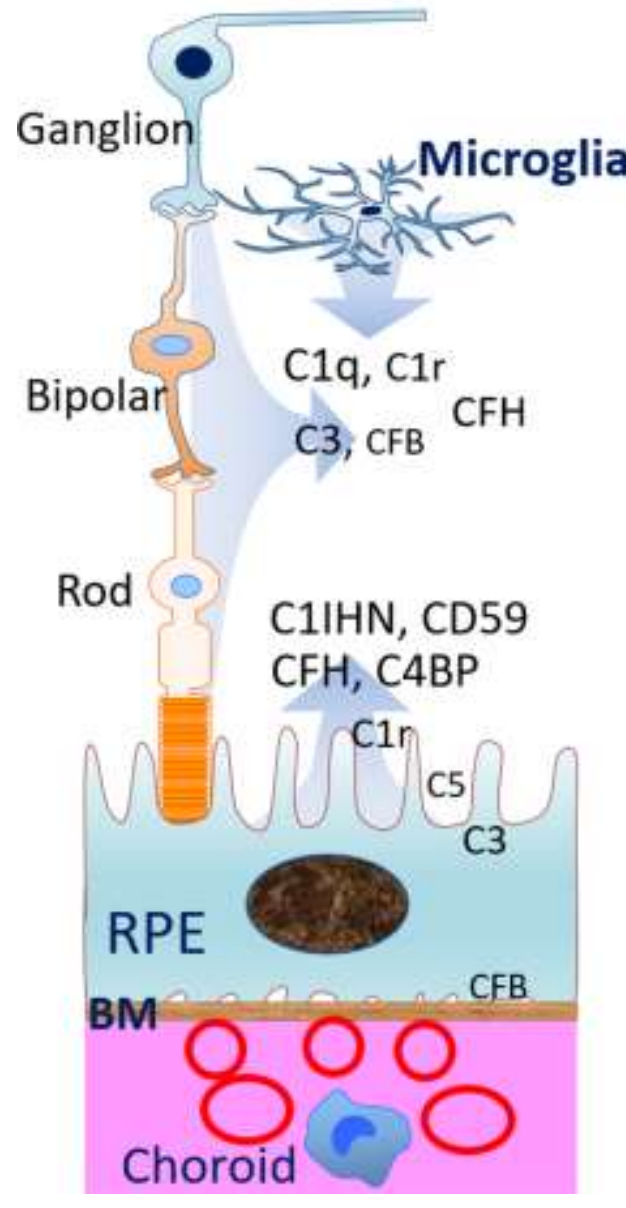

B Old

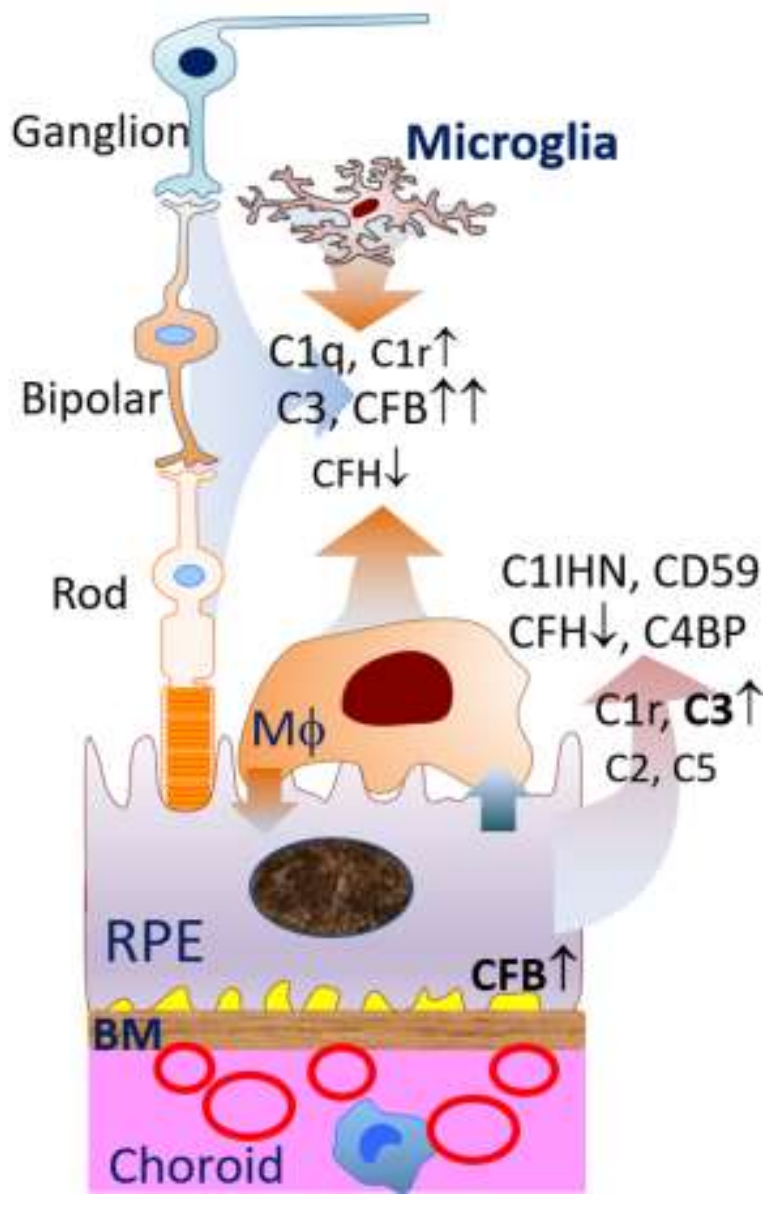

